\title{
Spatial and temporal resolution of carbon flux estimates for 1983-2002
}

\author{
L. M. P. Bruhwiler ${ }^{1}$, A. M. Michalak ${ }^{2}$, and P. P. Tans ${ }^{1}$ \\ ${ }^{1}$ NOAA Earth System Research Laboratory, Global Monitoring Division, Boulder, Colorado, USA \\ ${ }^{2}$ Department of Civil and Environmental Engineering, University of Michigan, Ann Arbor, MI, USA
}

Received: 23 October 2007 - Published in Biogeosciences Discuss.: 20 December 2007

Revised: 11 April 2011 - Accepted: 18 April 2011 - Published: 26 May 2011

\begin{abstract}
We discuss the spatial and temporal resolution of monthly carbon flux estimates for the period 19832002 using a fixed-lag Kalman Smoother technique with a global chemical transport model, and the GLOBALVIEW data product. The observational network has expanded substantially over this period, and the flux estimates are better constrained provided by observations for the 1990's in comparison to the 1980's. The estimated uncertainties also decrease as observational coverage expands. In this study, we use the Globalview data product for a network that changes every $5 \mathrm{yr}$, rather than using a small number of continuallyoperating sites (fewer observational constraints) or a large number of sites, some of which may consist almost entirely of extrapolated data. We show that the discontinuities resulting from network changes reflect uncertainty due to a sparse and variable network. This uncertainty effectively limits the resolution of trends in carbon fluxes, and is a potentially significant source of noise in assimilation systems that allow changes in observation distribution between assimilation time steps.

The ability of the inversion to distinguish, or resolve, carbon fluxes at various spatial scales is examined using a diagnostic known as the resolution kernel. We find that the global partition between land and ocean fluxes is well-resolved even for the very sparse network of the 1980's, although prior information makes a significant contribution to the resolution. The ability to distinguish zonal average fluxes has improved significantly since the 1980 's, especially for the tropics, where the zonal ocean and land biosphere fluxes can be distinguished. Care must be taken when interpreting zonal average fluxes, however, since the lack of air samples for some regions in a zone may result in a large influence from
\end{abstract}

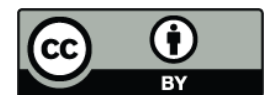

Correspondence to: L. M. P. Bruhwiler (lori.bruhwiler@noaa.gov) prior flux estimates for these regions. We show that many of the TransCom 3 source regions are distinguishable throughout the period over which estimates are produced. Examples are Boreal and Temperate North America. The resolution of fluxes from Europe and Australia has greatly improved since the 1990's. Other regions, notably Tropical South America and the Equatorial Atlantic remain practically unresolved.

Comparisons of the average seasonal cycle of the estimated carbon fluxes with the seasonal cycle of the prior flux estimates reveals a large adjustment of the summertime uptake of carbon for Boreal Eurasia, and an earlier onset of springtime uptake for Temperate North America. In addition, significantly larger seasonal cycles are obtained for some ocean regions, such as the Northern Ocean, North Pacific, North Atlantic and Western Equatorial Pacific, regions that appear to be well-resolved by the inversion.

\section{Introduction}

Atmospheric carbon dioxide has increased over the industrial period by about $100 \mathrm{ppm}$, and is expected to double by approximately the middle of this century (Houghton et al., 2001). Since the start of high precision $\mathrm{CO}_{2}$ measurements in the mid-20th century, it has become apparent that, thus far, only about $60 \%$ of emissions from fossil fuel burning have remained in the atmosphere, the rest having been taken up by the oceans and the terrestrial biosphere. Long-term network observations of carbon dioxide have suggested considerable interannual variability in the fluxes of carbon, especially for land ecosystems (e.g. Keeling and Shertz, 1992; Tans et al., 1989; Conway et al., 1994). Quantifying and locating carbon fluxes and trends is of critical importance considering the role $\mathrm{CO}_{2}$ plays in determining climate, and the numerous

Published by Copernicus Publications on behalf of the European Geosciences Union. 
possible feedbacks involving carbon that may play out in the future oceans and biosphere.

The information available from global network observations has increased dramatically over time. In the 1980's, a limited number of network sites were able to reveal an upward trend, large seasonal cycles and significant interannual variability (e.g. Keeling et al., 1995; Conway et al., 1994). As the number of sites increased, it became possible to obtain information about the latitudinal gradients of $\mathrm{CO}_{2}$. This led to the deduction of a carbon sink at temperate latitudes of the Northern Hemisphere since the observed gradient was found to be smaller than that expected from the latitudinal distribution of fossil fuel emissions. Further analysis led to the conclusion that this carbon sink is predominantly located in the northern hemispheric terrestrial biosphere (Tans et al., 1990).

The focus of much recent research has been on determining carbon fluxes at continental and ocean basin scales, or even regional scales, using inverse techniques (e.g. Rayner and Law, 1999; Bousquet et al., 2000; Gurney et al., 2002; Kaminski et al., 1999; Rödenbeck et al., 2003a; Baker et al., 2006; Michalak et al., 2004). These methods use transport models to predict the spatial and temporal behavior of atmospheric $\mathrm{CO}_{2}$, which is then compared with network observations. The resulting differences are used to deduce carbon fluxes. Because of the relatively sparse and uneven distribution of network sites and because of the diffusive and ill-constrainted nature of atmospheric transport, the flux estimation problem is usually well-constrained for some source regions and minimally constrained for others. In order to avoid physically unrealistic solutions for unconstrained regions, Bayesian estimation techniques have been employed, wherein the solution is constrained by a weighted combination of observations and prior flux estimates or prior assumptions about the spatial and temporal correlation of fluxes (Enting et al., 1995; Michalak et al., 2004). The extent to which the inversion is pulled toward observational relative to prior constraints is determined by the balance between input observational and transport model uncertainties and prior flux uncertainties. It should be noted that the transport model uncertainties described here also includes the possible inability of the transport model to simulate variability arising from local sources not resolved by the model. Accurate determination of these uncertainties is problematic and the flux estimates are sensitive to choices of these quantities (e.g. Michalak et al., 2005).

The observational network has changed over time, expanding from about 25 sites in the early 1980's to well over 100 more recently. This presents a challenge for inverse calculations, since flux estimates are sensitive to the composition of the network due to sparse coverage even for current networks. One is generally forced to choose either a few sites with long, continuous data records, to use many sites and include significant amounts of extrapolated data, or to use a variable network which may produce abrupt changes in the solution. As we will demonstrate, the ability of the inversion to resolve source regions improves for many regions using recent networks. In this study, we therefore adopt the approach of using a variable network, and we argue that the discontinuities due to changes in the network are symptomatic of sampling uncertainty that effectively limits the retrieval of information about long-term changes in the global carbon budget. We also point out that currently, quasi-operational assimilation schemes, such the NOAA's CarbonTracker (http: //www.esrl.noaa.gov/gmd/ccgg/carbontracker/), that assimilate observations as they are available are likely to produce unrealistic variability in flux estimates due to network changes and this noise is currently not quantified. Although the subject of changing networks as been addressed in past studies (e.g. Rödenbeck et al., 2003b; Gurney et al., 2008, among others), we take the approach in this study of highlighting how the ability to obtain spatially explicit source information has changed over time, and which source regions and aggregations become more reliable.

Relatively little is understood quantitatively about the specific biases in transport models, but observations are weighted by estimates of these errors (model-data mismatch errors) in inversions and the resulting solution is sensitive to the values chosen. Differing answers may be found in the literature due to varying methodologies and choices for input parameters. For example, the study of Fan et al. (1998) estimated fluxes for a few regions using hard constraints on other regions, and obtained a large uptake $\left(1.7 \mathrm{GtC} \mathrm{yr}^{-1} \pm 0.5 \mathrm{GtC} \mathrm{yr}^{-1}\right)$ for North America and a

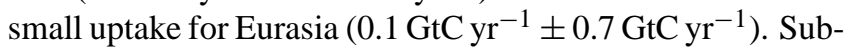
sequent studies found larger sinks over Eurasia, or fluxes that are more evenly distributed over land regions (e.g. Rayner and Law, 1999; Bousquet et al., 2000; Gurney et al., 2002, 2003, 2004; Peylin et al., 2002). The sizes of the networks used for these studies ranges from only 13 sites to 77 and the number of regions solved for varied from 7 to 22 regions. The time periods over which fluxes are estimated or averaged also varies from study to study, making direct comparisons somewhat difficult. Some studies, such as Peters et al. (2005), Kaminski et al. (1999), Rödenbeck et al. (2003a) and Michalak et al. (2004), have taken the approach of solving for fluxes of $\mathrm{CO}_{2}$ at very fine spatial resolution, followed by aggregation to larger regions with smaller estimated errors. This strategy has the advantage of reducing aggregation errors (Kaminski et al., 2001). The use of prior information, either in the form of assumptions about the fluxes themselves or the spatial or temporal covariance of the fluxes, are essential to the success of these methods.

The extent to which the global observational network is able to resolve flux information at various spatial and temporal scales is the topic of this study. In particular, how well and where can longitudinal variations in carbon fluxes be constrained? Can continental fluxes be distinguished from fluxes from neighboring ocean regions? Does the observational network even constrain the global partition between 
land and ocean fluxes? Can trends and interannual variability in fluxes be extracted reliably from multi-decadal inversions?

In the next section, we briefly describe the transport model and inversion technique used for this study. This is followed by a short discussion of the rationales for choices of prior flux estimates and uncertainties, model-data mismatch error, and observational networks used for the inversions. In Sect. 4, we describe a useful diagnostic, the resolution kernel, which may be used to interpret the flux estimates. Inversion results at various spatial scales are described in Sect. 5, along with flux estimates at the underlying inversion resolution of 22 source regions. In each case we consider the results in light of what the resolution kernel implies we should be able to resolve at the various spatial scales. We also use the resolution kernel to show how our ability to distinguish source regions has improved with the addition of more observation sites over time. Finally, we discuss how the average seasonal cycle for each region diverges from the prior.

\section{The transport model and flux estimation technique}

The transport model used for this study is the coarse grid Tracer Model version 3 (TM3). The horizontal resolution is roughly $7.5^{\circ} \times 10^{\circ}$, with 9 vertical levels spanning the surface to $10 \mathrm{hPa}$. The TM3 global transport model may be driven by either analyzed meteorological fields or those calculated by a general circulation model. The transport model is described in detail by Heimann and Koerner (2003). TM3 integrates the tracer continuity equation with a $3 \mathrm{~h}$ time step for an arbitrary number of tracers using the slopes advection scheme of Russell and Lerner (1981). Also included are stability-dependent vertical diffusion using the parameterization of Louis (1979), and a detailed convective mass transport scheme by Tiedke (1989). As noted by Denning et al. (1999) in a model intercomparison study of the inert atmospheric tracer $\left(\mathrm{SF}_{6}\right)$, TM3 lies within the group of models that tend to have weak vertical mixing. This has implications for flux estimation and could produce biases. For example, weak vertical mixing during autumn, when respiration of $\mathrm{CO}_{2}$ from the biosphere is high, may result in a calculated overabundance of $\mathrm{CO}_{2}$ in the atmospheric boundary layer relative to observations. This will lead to flux estimates with artificially low estimates of $\mathrm{CO}_{2}$ emission. During the summer, convection that is too weak may result in lower than observed predicted $\mathrm{CO}_{2}$, and underestimated carbon uptake.

Use of coarse resolution transport allows us to do many calculations quickly. In this study, we are interested in estimating monthly average fluxes using monthly average observations. Use of higher resolution transport fields are therefore not likely to impact the results discussed here significantly, except that some observation sites may be excluded from our inversions because the transport at these sites cannot be adequately simulated with a coarse resolution model. This will be discussed in more detail in Sect. 3. The wind fields used to calculate mass fluxes in this study are the National Center for Environmental Prediction (NCEP) reanalysis products from 1983 through 2001.

The inversion technique we use for this study is the Kalman Smoother described by Bruhwiler et al. (2005). This computationally efficient method for estimating carbon fluxes over multiple decades makes use of the fact that the observations that most strongly constrain monthly fluxes are those within about a half a year of emission, since basis functions (calculated as unit pulses emitted over a month from a particular source region) have the most structure and largest spatial gradients within a few months of emission. The pulses are rapidly dispersed by atmospheric transport, eventually reaching a steady background value. Therefore the basis functions need only be transported for a limited amount of time (6 months in this study) compared to several years (with extrapolation beyond this over the entire inversion period) for the commonly used Bayesian synthesis inversion technique. Results using the fixed-lag Kalman Smoother yield excellent agreement with the Bayesian synthesis technique (Bruhwiler et al., 2005). Furthermore, the sizes of the matrices used in the inversion are significantly smaller, thus reducing computation cost. The numerical efficiencies of the Kalman smoother in turn make it possible to perform large numbers of multi-decadal inversions in order to test sensitivities to parameters and networks.

\section{Method}

Multiple studies have demonstrated the sensitivity of atmospheric inversions to input parameters and solution strategies (e.g. Peylin et al., 2002; Rödenbeck et al., 2003a; Michalak et al., 2004; Krakauer et al., 2004). As these studies have shown, assumptions about the model-data mismatch and prior flux uncertainties have a significant impact on estimates of fluxes and uncertainties. The size and composition of the observational network also has a large impact on the estimated fluxes, and in some cases, the addition of a single site can drastically alter the partitioning of fluxes between adjacent regions (Yuen et al., 2005). The latter problem arises because the current distribution of observational sites is still very sparse and does not adequately sample the source variability.

In this section, we describe the input parameters and network compositions for the calculations presented in this study. In the sections that follow, we discuss our flux estimates for the underlying spatial resolution: the TransCom 3 source regions (shown in Fig. 1), and results aggregated to global and zonal scales.

\subsection{Prior flux estimates and uncertainties}

Here we describe the a priori flux estimates used in this study and their uncertainties. A diagonal a priori covariance matrix 


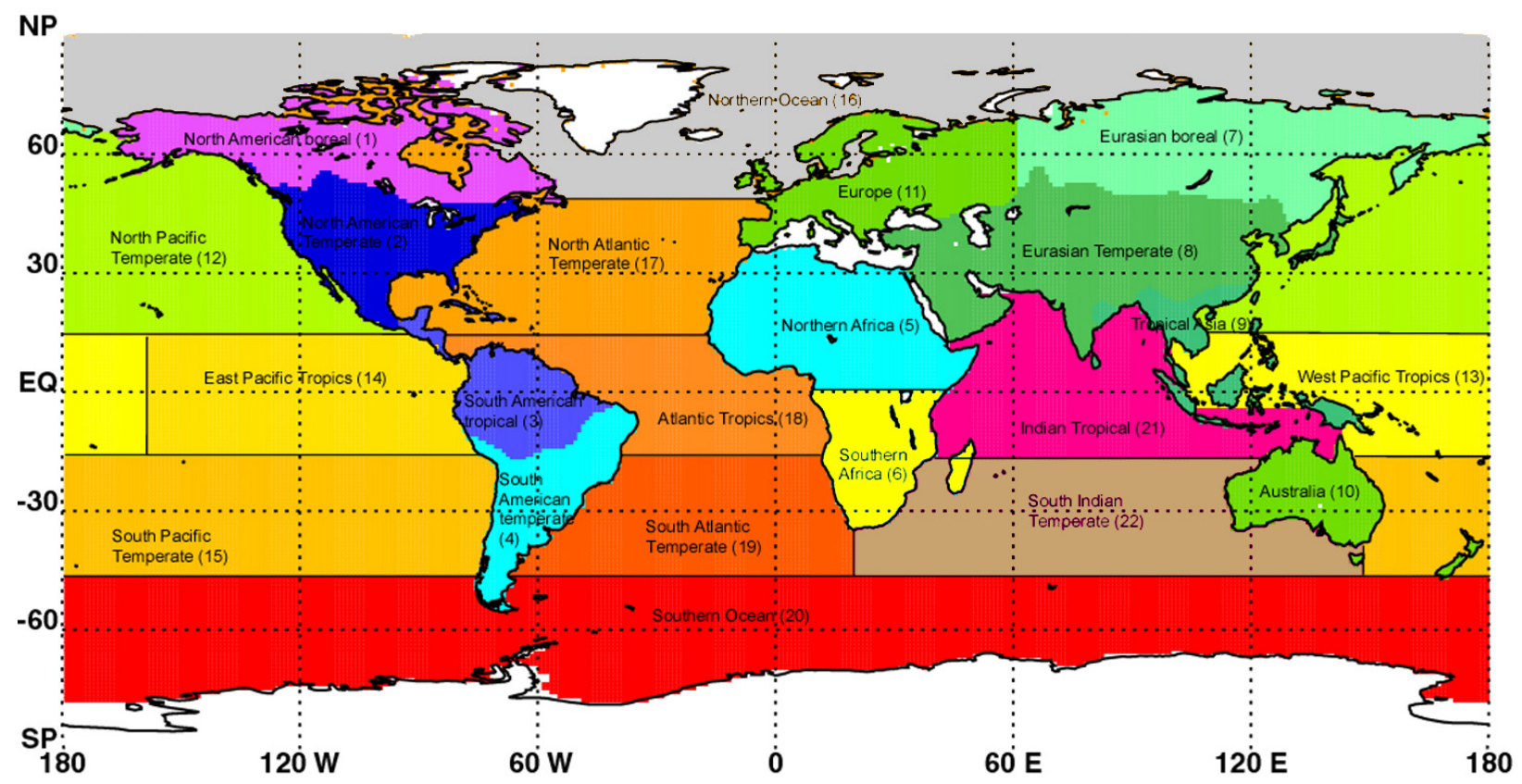

Fig. 1. The TransCom 3 flux regions (source: Kevin Gurney, http://www.purdue.edu/transcom/).

is used such that the spatial and temporal covariances between the estimated parameters is initially zero.

The prior flux estimates for the oceans adopted in this study are those of Takahashi et al. (1999), who used shipboard measurements of $p \mathrm{CO}_{2}$ in surface waters collected since 1960 (approximately 2.5 million data points) to calculate the sea-air $p \mathrm{CO}_{2}$ difference on a $4^{\circ}$ latitude by $5^{\circ}$ longitude grid. Horizontal advection and diffusion fields from an ocean general circulation model were used to interpolate values for grid boxes where no observations exist. The net airsea $\mathrm{CO}_{2}$ flux was estimated by using monthly mean winds and the Wanninkhof (1992) formulation of the effect of wind speed on the gas transfer coefficient. Since for any particular year the data coverage is sparse, the entire data set was used to construct $\mathrm{CO}_{2}$ fluxes for one composite non-El Niño year, 1995 , by correcting for the atmospheric $\mathrm{CO}_{2}$ trend. The estimate of the annual global ocean net uptake of $\mathrm{CO}_{2}$ for this data set is $2.2 \mathrm{GtC} \mathrm{yr}^{-1}$.

An important source of uncertainty in the air-sea $\mathrm{CO}_{2}$ fluxes is the estimated gas transfer coefficient and its dependence on wind speed. Interpolation of the relatively sparse data set in space and time is also a source of error. Takahashi et al. (2002) estimate that the error due to interpolation is as large as $50 \%$, with an additional $20 \%$ uncertainty associated with the wind speed dependence of the gas transfer coefficient. In this study, we have chosen to use a nominal uncertainty of $100 \%$ of the monthly prior flux for each ocean region with a lower limit of $0.2 \mathrm{GtC} \mathrm{yr}^{-1}$ (note that the flux units are always expressed in $\mathrm{GtC} \mathrm{yr}^{-1}$ even if they are applied only over 1 month).
For the terrestrial biosphere, annually-balanced carbon fluxes calculated using the Carnegie-Ames-Stanford Approach (CASA) model were used (Randerson et al., 1997) as prior flux estimates. The CASA model consists of a simulation of net primary productivity (NPP) and a submodel that calculates heterotrophic respiration. Inputs to the CASA model include normalized difference vegetation index (NDVI) from satellite observations, surface solar insolation, climatological temperature and precipitation, soil texture and land cover classification derived from NDVI. The steadystate net ecosystem production (NEP), which is intended to represent 1990, was calculated by running the model for $5000 \mathrm{yr}$ in order to allow the plant, litter and soil carbon pools to equilibrate. Due to the fact that the biosphere is in equilibrium for this CASA simulation, the annual net global land biospheric uptake of $\mathrm{CO}_{2}$ is approximately zero.

Estimating the uncertainty of the $\mathrm{CASA} \mathrm{CO}_{2}$ fluxes is difficult. Potential sources of uncertainty are errors in the input fields, and errors and biases in both the NPP and heterotrophic respiration model components. The global spatial variability of NPP is captured quite well since satellite observations are used. Note that atmospheric data used in the inversion have also been used to evaluate the CASA model, therefore the prior fluxes and observations may not be strictly independent. In this study, we have chosen to use a nominal uncertainty of $100 \%$ of the monthly NEP with a lower limit of $1 \mathrm{GtC} \mathrm{yr}^{-1}$ for land regions. We also assume normallydistributed prior flux uncertainties, althoughChevallier et al. (2006) have suggested based on comparison of a prognostic terrestrial biosphere model with flux tower observations 
that the prior flux errors may be better represented by a nonnormal distribution. The treatment of non-normal error distributions is beyond the scope of the present study.

\subsection{Model-data mismatch error}

The model-data mismatch error represents the ability of the transport model to accurately represent transport processes and local source variability at each measurement site. This type of error is significantly larger than the observational errors of the flask network. Choosing appropriate values for the model-data mismatch error is difficult because there are insufficient independent data available for detailed model evaluation at each measurement site. Furthermore, errors in the transport model can cause covariance in the model-data mismatch error which ideally also ought to be taken into account Chevallier (2007). It is likely that the spatially sparse and low frequency observations used here will help limit the importance of observational error covariance. $\mathrm{CO}_{2}$ profile observations from tall towers and aircraft were aggregated and de-weighted in the inversion to correspond with the model's relatively coarse vertical resolution. Most of the aircraft observations are obtained in the free troposphere where horizontal transport dominates, hopefully limiting the effect of vertical transport error covariance.

We have evaluated the agreement between observations and forward simulations of $\mathrm{CO}_{2}$ in order to estimate how well each site is simulated. Forward simulations were done using the fossil fuel inventory of Andres et al. (1996) and Brenkert (1998) along with the biospheric and ocean fluxes described above and later used as prior flux estimates in the inversion. We first calculate long-term means and average seasonal cycles for both the modeled and observed $\mathrm{CO}_{2}$ time series. Differences in the long-term means and average seasonal cycles likely arise from differences between the prior fluxes and the actual fluxes, while differences between the short period deviations from the long-term mean and annual cycle between the observed and modeled $\mathrm{CO}_{2}$ time series likely arise from misrepresentation of local sources and transport processes (i.e., model-data mismatch errors). These residual deviations are used to obtain a relative measure of how well the model is able to reproduce the monthly $\mathrm{CO}_{2}$ time series at each site. Model-data mismatch errors are estimated by weighting the scaled residual deviations to give chi-squared values close to 1 in the inversion. This method of constructing a set of model-data mismatch errors is similar to weighting sites according to observed variability, however, it allows for the fact that at least some of the observed variability, that occurring on seasonal timescales, is actually resolved by the transport model and that this information can be used to revise the prior flux estimates.

We also point out that the framework used for the calculations described here uses basis functions that have imposed within-region spatial patterns calculated from the prior flux distributions. Strictly speaking, this results in the imposition of a hard constraint on the solution with possible resulting biases as described by Engelen et al. (2002).

The posterior fits to the observations have also been used to infer which sites the transport model may be unable to simulate well. In particular, the contribution of each site to the cost function may be calculated to determine how well each site was fit by the inversion (e.g. Peylin et al., 2002). If this parameter for a particular site is significantly larger than for typical sites that are relatively easy to model, then that site may be de-weighted in the inversion. We found that sites that the inversion had trouble fitting were also sites with known modeling complications, such as those sites close to local sources, or those subject to small-scale transport features such as sea and mountain-valley breezes. Examples are Grifton, North Carolina and Sary Taukum, Kazakhstan. Exluded sites are pinpointed in red in Fig. 2.

\subsection{Selection of observation sites}

The observations used in this study are those of the Cooperative Air Sampling Network, which is coordinated by the National Oceanic and Atmospheric Administration Earth System Research Laboratory Global Monitoring Division (NOAA-ESRL/GMD, formerly the NOAA Climate Monitoring and Diagnostics Laboratory). This network consists of sites from multiple international collaborators, and includes high frequency measurements from the 5 NOAA Baseline Observatories (Mauna Loa, Point Barrow, Trinidad Head, Samoa and the South Pole), weekly aircraft profiles, regular shipboard observations, measurements from tall towers and weekly duplicate air samples from fixed points around the globe. Samples are analyzed at NOAA-ESRL/GMD, and the process is subject to careful calibration and data quality controls. The observations are freely available on the internet (www.esrl.noaa.gov/gmd/dv/data). The observations are described in detail by Conway et al. (1994).

In order to provide uninterrupted records of $\mathrm{CO}_{2}$ abundance for use in atmospheric inversions, Masarie and Tans (1995) devised a technique to extrapolate and interpolate time series of observations over periods for which measurements at a particular site do not exist. Application of this data extension procedure for the network results in the data product known as "GLOBALVIEW", the construction of which involves application of the analysis tools described by Thoning et al. (1989). Information such as long-term trends, average seasonal cycles and filtered residuals from nearby measurement sites are used to fill in missing data, extrapolating back to 1979 if necessary. In extreme cases, such as recently established sites, the GLOBALVIEW product may consist almost entirely of extrapolated observations; however, information is provided on whether actual observations are used to produce the smoothed data. Strictly speaking, the use of this data product results in multiple use of data, since nearby sites are used to fill in the missing data before being used 
1985

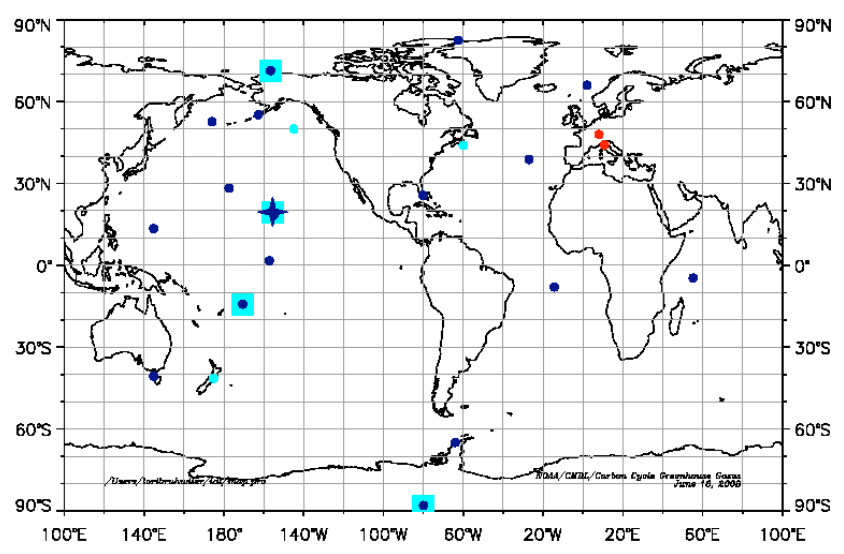

1995

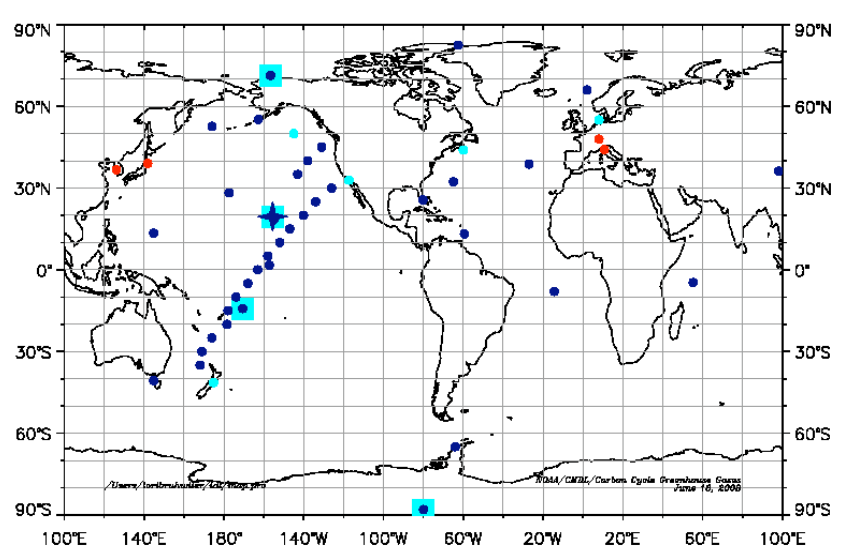

1990

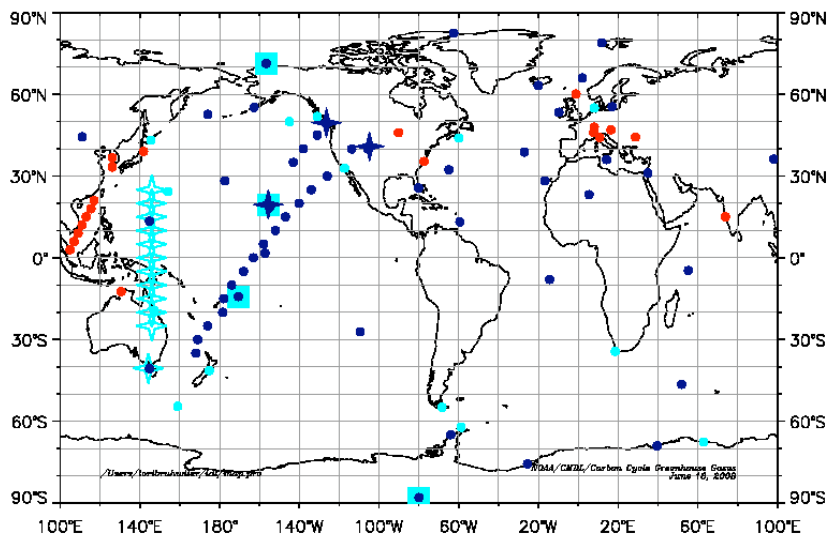

2000

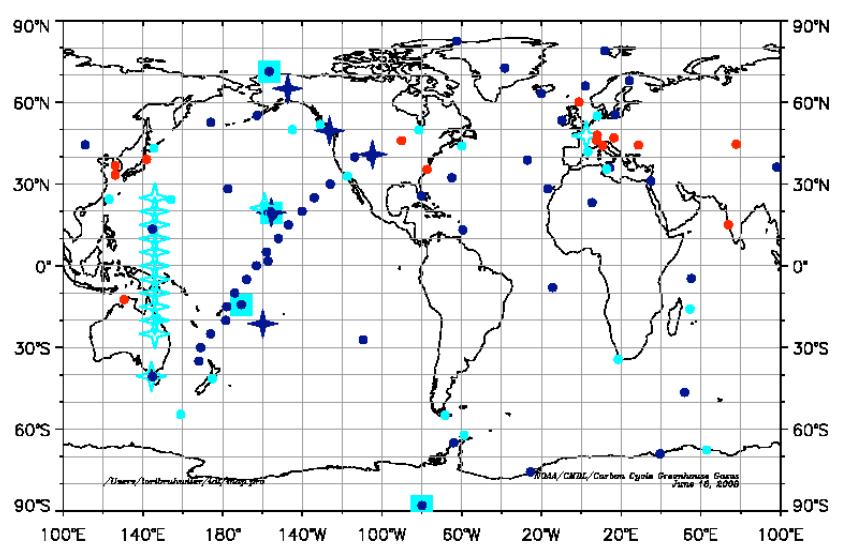

Fig. 2. Changes in the observational networks over time. The dark blue circles show the locations where flask samples are routinely taken and the large light blue squares show the locations of CMDL observatories where high frequency measurements are also available. Red circles are measurement sites that were not used because the transport model could not simulate them well. Aircraft sampling sites are shown as dark blue stars.

again in the flux estimation. The net result is that some data have effectively more weight in the inversions.

One strategy that is often employed to deal with significant gaps in data records is to use sites that have nearly continuous observations over the entire period for which fluxes are being estimated. Hence, if the carbon fluxes over the period 1980 to 2000 are being estimated, then only those sites that have a high percentage of actual measurements over this time span are used. As Fig. 2 shows, however, during the mid-1980's, the observing network was very sparse. The number of sites has increased significantly over time, with the largest network expansion occurring in the early 1990's. As we will show, even for this period large and potentially important regions remain only indirectly constrained by observations. Although using a small network consisting of sites with nearly continuous data avoids multiple use of observations, the results of the inversion are inevitably more dependent on prior flux estimates since less data is used to constrain the inversion.
When first conceived, the observational network was intended to make weekly long-term measurements of longlived atmospheric species at remote locations in order to monitor the composition of the "background" atmosphere. Hence, sites were located in remote locations where predominantly pristine marine boundary layer air could be sampled. Over time, the realization that continental air must be sampled in order to adequately constrain terrestrial biospheric fluxes at continental scales has led to an increase in the number of sites that sample air influenced directly by terrestrial processes. Unfortunately, these sites are also the most difficult for the transport models to simulate well, and many of these sites are not currently used in global atmospheric inversions. As models improve, it will become possible to use more of these sites.

In this study, we have adopted a compromise between using only existing observations (a sparse network) and using a large number of sites with extrapolated/interpolated data, a strategy similar to Rödenbeck et al. (2003a) and 
Peylin et al. (2005). We define four networks representing the 1980's (29 sites), 1990-1995 (48 sites), 1995-2000 (103 sites) and 2000-2002 (120 sites). A list of these sites, and time periods over which each is used is given in Table 1. The last column of Table 1 gives the model-data mismatch error chosen for each site. Sites that are not well-simulated by the transport model were excluded from each network as described in the previous section and are shown as red symbols in Fig. 2. Use of these changing networks results in abrupt adjustments in the flux estimates at the transitions between the networks, and reflects the uncertainty due to sparse and variable networks which effectively limits the ability to characterize any flux trends.

\section{The resolution kernel}

A useful diagnostic of flux estimation frameworks is the resolution kernel (e.g. Backus and Gilbert, 1970; Tarantola, 1987; Menke, 1989; Rodgers, 2000). This quantity indicates the degree to which the estimated parameters can be resolved independently, and is equivalent to the averaging kernel matrix used in satellite retrievals. The resolution kernel may be obtained by assuming that the true, but unknown, values of the parameter being estimated, $\boldsymbol{s}_{\text {true }}$, are related to (error-free) observations, $z$, by

$z=\mathbf{H} \boldsymbol{s}_{\text {true }}$

where $\mathbf{H}$ in this context is a matrix of the responses at each measurement site from unit pulses emitted from each source region.

The discrete Kalman filter update equation for the estimated source vector is (Kalman, 1960; Gelb, 1974)

$\boldsymbol{s}^{\prime}=\boldsymbol{s}_{\mathrm{p}}+\mathbf{Q} \mathbf{H}^{T}\left[\mathbf{R}+\mathbf{H Q} \mathbf{H}^{T}\right]^{-1}\left(z-\mathbf{H} \boldsymbol{s}_{\mathrm{p}}\right)$

where $\mathbf{Q}$ and $\mathbf{R}$ are prior flux and model-data mismatch error covariance matrices, $s_{\mathrm{p}}$ is a vector of prior flux estimates, and $s$ ' is a vector of posterior flux estimates.

Equations (1) and (2) may be combined as

$\boldsymbol{s}^{\prime}-s_{\mathrm{p}}=\mathcal{R}\left(s_{\text {true }}-s_{\mathrm{p}}\right)$

where the resolution kernel is identified as

$\mathcal{R}=\mathbf{Q} \mathbf{H}^{T}\left[\mathbf{R}+\mathbf{H Q} \mathbf{H}^{T}\right]^{-1} \mathbf{H}=\mathbf{K H}$

and $\mathbf{K}$ is the Kalman gain matrix. The resolution kernel is a square matrix with rank equal to the number of parameters estimated.

Note also that using the update equation for the covariance,

$\mathbf{Q}^{\prime}=\mathbf{Q}-\mathbf{Q} \mathbf{H}^{T}\left[\mathbf{R}+\mathbf{H} \mathbf{Q} \mathbf{H}^{T}\right]^{-1} \mathbf{H Q}$

implies

$\mathbf{Q}^{\prime}=(\mathbf{I}-\mathcal{R}) \mathbf{Q}$
Individual rows of $\mathcal{R}$ show the relative extent to which each parameter may be distinguished from the other estimated parameters. $\mathcal{R}$ quantifies the ability to retrieve the true parameters, with limitations due to transport errors, non-resolved local source variability and the sparseness of observations.

\subsection{Limiting behavior of $\mathcal{R}$ and dependence on input parameters}

It is instructive to consider the resolution kernel in terms of idealized limiting cases that show how the ability to resolve fluxes is affected by uncertainties in prior fluxes and the model-data mismatch error. A related issue is the sparse observation network which also affects resolution through population of the response function matrix, $\mathbf{H}$.

In the limit that $\mathbf{H}$ is a square, non-singular matrix (a singular matrix would be unphysical) and $\mathbf{R}$ approaches 0 (perfect transport and no observational error), $\mathcal{R}$ approaches $\mathbf{Q} \mathbf{H}^{T}\left(\mathbf{H}^{T}\right)^{-1} \mathbf{Q}^{-1} \mathbf{H}^{-1} \mathbf{H}=\mathbf{I}$. In this case, the estimated parameters are perfectly distinguishable. From Eqs. (3) and (6), it is clear that if $\mathcal{R}=\mathbf{I}$ then we obtain the true values of the estimated parameters with zero uncertainty, the ideal situation. Each row of the resolution kernel gives a value of 1.0 for the element corresponding to the estimated parameter, and 0.0 elsewhere, indicating no confusion of the solution with those of other estimated parameters.

On the other hand, if $\mathbf{R} \gg \mathbf{Q}(\mathbf{Q} \approx 0.0)$, then $\mathcal{R}$ goes to 0.0 . The estimated parameters are not resolved for this case, and the estimated fluxes and their uncertainties are unchanged from prior values and uncertainties. No new information is obtained about the estimated parameters. This may also be seen from Eq. (6).

The dependence of parameter resolution on the density of observations influences $\mathcal{R}$ through the products involving $\mathbf{H}$, which is generally not square or non-singular. Source regions not well-sampled by the observational network will have corresponding small elements in $\mathbf{H}$. In the limit that $\mathbf{H}$ actually goes to zero, $\mathcal{R}$ will also go to zero, and the estimated parameters are not resolved and the parameters and uncertainties remain at their prior values.

Atmospheric inversion problems tend to have a mixture of parameters that are well-constrained by observations, and parameters for which the estimates and uncertainties do not deviate significantly from the prior values. $\mathcal{R}$ is therefore composed of some rows for which the element corresponding to an estimated parameter is nearly 1.0 with small off-diagonal values, and some rows for which there are numerous peaks, and some rows for which all values are nearly zero.

Note that computation of the resolution kernel uses quantities that are pre-calculated or input into the inversion, therefore, the full parameter estimation need not be done to assess how well parameters will be resolved by a particular framework. In subsequent sections, we show how the application of the resolution kernel leads to useful and important 
Table 1. Observation Sites.

\begin{tabular}{|c|c|c|c|c|c|}
\hline Site Code & 1985 & 1990 & 1995 & 2000 & $\begin{array}{l}\text { Model-Data } \\
\text { Mismatch Error }\end{array}$ \\
\hline AIA005 & & & $X$ & $X$ & 0.4 \\
\hline AIA015 & & & $X$ & $X$ & 0.4 \\
\hline AIA025 & & & $X$ & $X$ & 0.4 \\
\hline AIA035 & & & $X$ & $X$ & 0.4 \\
\hline AIA045 & & & $X$ & $X$ & 0.4 \\
\hline AIA055 & & & $X$ & $X$ & 0.4 \\
\hline AIA065 & & & $X$ & $X$ & 0.4 \\
\hline ALT & $X$ & $X$ & $X$ & $X$ & 0.6 \\
\hline AMS & $X$ & & & & 0.4 \\
\hline ASC & $X$ & $X$ & $X$ & $X$ & 0.5 \\
\hline ASK & & & $X$ & $X$ & 0.5 \\
\hline AVI & $X$ & & & & 0.5 \\
\hline AZR & $X$ & $X$ & $X$ & $X$ & 0.6 \\
\hline BAL & & & $X$ & $X$ & 1.0 \\
\hline BGU & & & $X$ & $X$ & 1.1 \\
\hline BHD & $X$ & $X$ & $X$ & $X$ & 0.4 \\
\hline BME & & $X$ & $X$ & $X$ & 0.6 \\
\hline BMW & & $X$ & $X$ & $X$ & 0.6 \\
\hline BRW & $X$ & $X$ & $X$ & $X$ & 0.6 \\
\hline BSC & & & & & 1.0 \\
\hline CAR030 & & & $X$ & $X$ & 0.5 \\
\hline CAR040 & & & $X$ & $X$ & 0.4 \\
\hline CAR050 & & & $X$ & $X$ & 0.4 \\
\hline CAR060 & & & $X$ & $X$ & 0.4 \\
\hline CAR070 & & & $X$ & $X$ & 0.4 \\
\hline CAR080 & & & $X$ & $X$ & 0.4 \\
\hline CBA & $X$ & $X$ & $X$ & $X$ & 0.6 \\
\hline CFA & & & $X$ & $X$ & 0.5 \\
\hline CGO & $X$ & $X$ & $X$ & $X$ & 0.4 \\
\hline CHR & $X$ & $X$ & $X$ & $X$ & 0.4 \\
\hline CMN & & & & & 0.7 \\
\hline CMO & $X$ & $X$ & $X$ & & 0.6 \\
\hline COI & & & $\mathrm{X}$ & $X$ & 0.6 \\
\hline CPT & & & $X$ & $X$ & 0.4 \\
\hline CRI & & & & & 0.8 \\
\hline CRZ & & & $X$ & $X$ & 0.4 \\
\hline CSJ & $X$ & $X$ & $X$ & $X$ & 0.6 \\
\hline DAA & & & & & 0.6 \\
\hline EIC & & & & $X$ & 0.4 \\
\hline ESP & & & $X$ & $X$ & 0.7 \\
\hline FRD & & & $X$ & $X$ & 1.1 \\
\hline GMI & $X$ & $X$ & $\mathrm{X}$ & $X$ & 0.4 \\
\hline GOZ & & & & & 0.6 \\
\hline GSN & & & & & 0.8 \\
\hline HAA005 & & & & $X$ & 0.7 \\
\hline HAA015 & & & & $X$ & 0.6 \\
\hline HAA025 & & & & $X$ & 0.6 \\
\hline HAA035 & & & & $X$ & 0.6 \\
\hline HAA045 & & & & $X$ & 0.6 \\
\hline HAA055 & & & & $X$ & 0.6 \\
\hline HAA065 & & & & $X$ & 0.6 \\
\hline HAA075 & & & & $X$ & 0.6 \\
\hline HAT & & & $\mathrm{X}$ & $\mathrm{X}$ & 0.7 \\
\hline HBA & $X$ & $X$ & $X$ & $X$ & 0.4 \\
\hline
\end{tabular}

Table 1. Continued.

\begin{tabular}{|c|c|c|c|c|c|}
\hline Site Code & 1985 & 1990 & 1995 & 2000 & $\begin{array}{l}\text { Model-Data } \\
\text { Mismatch Error }\end{array}$ \\
\hline HUN00 & & & & & 1.0 \\
\hline HUN010 & & & & & 1.1 \\
\hline HUN048 & & & & & 1.1 \\
\hline HUN082 & & & & & 1.1 \\
\hline HUN115 & & & & & 1.4 \\
\hline ICE & & & $X$ & $X$ & 0.6 \\
\hline ITN & & & & & 0.8 \\
\hline ITN051 & & & & & 0.7 \\
\hline ITN123 & & & & & 0.8 \\
\hline IZO & & & $X$ & $X$ & 0.5 \\
\hline JBN & & & $X$ & $X$ & 0.4 \\
\hline KEY & $X$ & $X$ & $X$ & $X$ & 0.6 \\
\hline KUM & $X$ & $X$ & $X$ & $X$ & 0.5 \\
\hline KZD & & & & & 0.9 \\
\hline KZM & & & & & 0.8 \\
\hline LEF & & & & & 1.4 \\
\hline LEF011 & & & & & 0.9 \\
\hline LEF030 & & & & & 0.7 \\
\hline LEF076 & & & & & 0.8 \\
\hline LEF122 & & & & & 0.7 \\
\hline LEF244 & & & & & 0.7 \\
\hline LJO & & $X$ & $X$ & $X$ & 0.7 \\
\hline LMP & & & & $X$ & 0.6 \\
\hline MAA & & & $X$ & $X$ & 0.4 \\
\hline $\mathrm{MBC}$ & $X$ & $\mathrm{X}$ & & & 0.6 \\
\hline MHD & & & $X$ & $X$ & 0.6 \\
\hline MID & $X$ & $X$ & $X$ & $X$ & 0.6 \\
\hline MLO & $X$ & $X$ & $X$ & $X$ & 0.4 \\
\hline MNM & & & $X$ & $X$ & 0.4 \\
\hline MQA & & & $X$ & $X$ & 0.4 \\
\hline NWR & $\mathrm{X}$ & $X$ & $X$ & $X$ & 0.5 \\
\hline OPW & $X$ & & & & 0.6 \\
\hline ORL005 & & & & $X$ & 0.9 \\
\hline ORL015 & & & & $X$ & 0.6 \\
\hline ORL025 & & & & $X$ & 0.5 \\
\hline ORL035 & & & & $X$ & 0.7 \\
\hline PALCBC & & & & & 1.1 \\
\hline PFA015 & & & & $X$ & 0.9 \\
\hline PFA025 & & & & $X$ & 0.7 \\
\hline PFA035 & & & & $X$ & 0.7 \\
\hline PFA045 & & & & $X$ & 0.7 \\
\hline PFA055 & & & & $X$ & 0.7 \\
\hline PFA065 & & & & $X$ & 0.8 \\
\hline PFA075 & & & & $X$ & 0.7 \\
\hline POCS35 & & $X$ & $X$ & $X$ & 0.5 \\
\hline POCS30 & & $X$ & $X$ & $X$ & 0.4 \\
\hline POCS25 & & $\mathrm{X}$ & $X$ & $X$ & 0.5 \\
\hline POCS20 & & $\mathrm{X}$ & $X$ & $X$ & 0.6 \\
\hline POCS15 & & $X$ & $X$ & $X$ & 0.5 \\
\hline POCS10 & & $X$ & $X$ & $X$ & 0.6 \\
\hline POCS05 & & $\mathrm{X}$ & $X$ & $X$ & 0.6 \\
\hline POC00 & & $\mathrm{X}$ & $X$ & $X$ & 0.7 \\
\hline POCN05 & & $X$ & $X$ & $X$ & 0.6 \\
\hline POCN10 & & $X$ & $X$ & $X$ & 0.4 \\
\hline
\end{tabular}


Table 1. Continued.

\begin{tabular}{|c|c|c|c|c|c|}
\hline Site Code & 1985 & 1990 & 1995 & 2000 & $\begin{array}{l}\text { Model-Data } \\
\text { Mismatch Error }\end{array}$ \\
\hline POCN15 & & $X$ & $X$ & $X$ & 0.5 \\
\hline POCN20 & & $X$ & $X$ & $X$ & 0.4 \\
\hline POCN25 & & $X$ & $X$ & $X$ & 0.4 \\
\hline POCN30 & & $X$ & $X$ & $X$ & 0.4 \\
\hline POCN35 & & $X$ & $X$ & & 0.4 \\
\hline POCN40 & & $X$ & $X$ & & 0.4 \\
\hline POCN45 & & $X$ & $X$ & & 0.4 \\
\hline PRS & & & & & 0.6 \\
\hline PSA & $X$ & $X$ & $X$ & $X$ & 0.4 \\
\hline RPB & & $X$ & $X$ & $X$ & 0.5 \\
\hline RTA005 & & & & $X$ & 0.4 \\
\hline RTA015 & & & & $X$ & 0.4 \\
\hline RTA025 & & & & $\mathrm{X}$ & 0.4 \\
\hline RTA035 & & & & $X$ & 0.4 \\
\hline RTA045 & & & & $X$ & 0.4 \\
\hline RYO & & & & & 0.7 \\
\hline SBL & $X$ & $X$ & $X$ & $X$ & 0.8 \\
\hline $\mathrm{SCH}$ & & & & & 0.6 \\
\hline SCSN03 & & & $X$ & & 0.5 \\
\hline SCSN06 & & & $X$ & & 0.5 \\
\hline SCSN09 & & & $X$ & & 0.4 \\
\hline SCSN12 & & & $X$ & & 0.5 \\
\hline SCSN15 & & & $X$ & & 0.5 \\
\hline SCSN18 & & & $X$ & & 0.5 \\
\hline SCSN21 & & & $X$ & & 0.7 \\
\hline SEY & $X$ & $X$ & $X$ & $X$ & 0.4 \\
\hline SHM & $X$ & $X$ & $X$ & $X$ & 0.8 \\
\hline SIS & & & & & 0.7 \\
\hline SMO & $\mathrm{X}$ & $X$ & $X$ & $X$ & 0.4 \\
\hline SPO & $X$ & $X$ & $X$ & $X$ & 0.4 \\
\hline STM & $X$ & $X$ & $X$ & $X$ & 0.6 \\
\hline
\end{tabular}

insights, however, we first provide more details about the resolution kernel and its properties.

\subsection{Relation of $\mathcal{R}$ to $Q$}

For the special case where $\mathbf{Q}_{\text {prior }}$ is a diagonal matrix, the diagonal elements of the posterior covariance matrix are given by

$q_{n n}^{\prime}=\left(1-r_{n n}\right) q_{n n}$

where $q_{n n}^{\prime}$ and $q_{n n}$ are diagonal elements of the posterior and prior error covariance matrices, and $r_{n n}$ is the corresponding diagonal element of the resolution kernel matrix. From this equation we can see that the prior parameter variance is reduced more as the resolution of the parameter increases. Similarly, it may be shown that the off-diagonal elements of the posterior error covariance are

$q_{n m}^{\prime}=r_{n m} q_{m m}$
Table 1. Continued.

\begin{tabular}{|c|c|c|c|c|c|}
\hline Site Code & 1985 & 1990 & 1995 & 2000 & $\begin{array}{l}\text { Model-Data } \\
\text { Mismatch Error }\end{array}$ \\
\hline STP & $X$ & $X$ & $X$ & $X$ & 0.4 \\
\hline SUM & & & & $X$ & 1.1 \\
\hline SYO & & & $X$ & $X$ & 0.4 \\
\hline TAP & & & & & 0.7 \\
\hline TDF & & & $X$ & $\mathrm{X}$ & 0.4 \\
\hline TRM & & & & $X$ & 0.6 \\
\hline UTA & & & $\mathrm{X}$ & $X$ & 0.6 \\
\hline UUM & & & $X$ & $X$ & 0.6 \\
\hline WES & & & & & 0.8 \\
\hline WIS & & & $X$ & $X$ & 0.8 \\
\hline WKT00 & & & & & 1.1 \\
\hline WKT030 & & & & & 1.1 \\
\hline WKT061 & & & & & 1.1 \\
\hline WKT122 & & & & & 1.1 \\
\hline WKT244 & & & & & 1.1 \\
\hline WKT457 & & & & & 1.1 \\
\hline WLG & & $X$ & $X$ & $X$ & 0.6 \\
\hline WPON30 & & & $X$ & $X$ & 0.6 \\
\hline WPON25 & & & $X$ & $X$ & 0.6 \\
\hline WPON20 & & & $X$ & $X$ & 0.4 \\
\hline WPON15 & & & $X$ & $X$ & 0.4 \\
\hline WPON10 & & & $X$ & $X$ & 0.4 \\
\hline WPON05 & & & $X$ & $X$ & 0.5 \\
\hline WPO00 & & & $X$ & $X$ & 0.5 \\
\hline WPOS05 & & & $X$ & $X$ & 0.5 \\
\hline WPOS10 & & & $X$ & $X$ & 0.5 \\
\hline WPOS15 & & & $X$ & $X$ & 0.5 \\
\hline WPOS20 & & & $\mathrm{X}$ & $X$ & 0.6 \\
\hline WPOS25 & & & $X$ & $X$ & 0.6 \\
\hline YON & & & & $X$ & 0.7 \\
\hline ZEP & & & $X$ & $X$ & 0.5 \\
\hline
\end{tabular}

Therefore, the posterior correlations between estimated parameters for a diagonal prior error covariance matrix are related to the variance of one parameter multiplied by the corresponding cross term from the resolution kernel. The latter gives a measure of how distinguishable the estimated parameter, $n$, is from $m$.

\section{Results}

In this section we describe inversions for carbon fluxes using the Fixed-Lag Kalman Smoother framework discussed by Bruhwiler et al. (2005), observations from the NOAA ESRL GMD Cooperative Air Sampling Network for 1983 through 2002, and the input uncertainties and prior flux estimates as described above. The underlying source resolution of the atmospheric inversions is 22 continental and ocean basin scale regions (TransCom 3 Model Intercomparison Experiment, Gurney et al., 2000). The results we show do not 

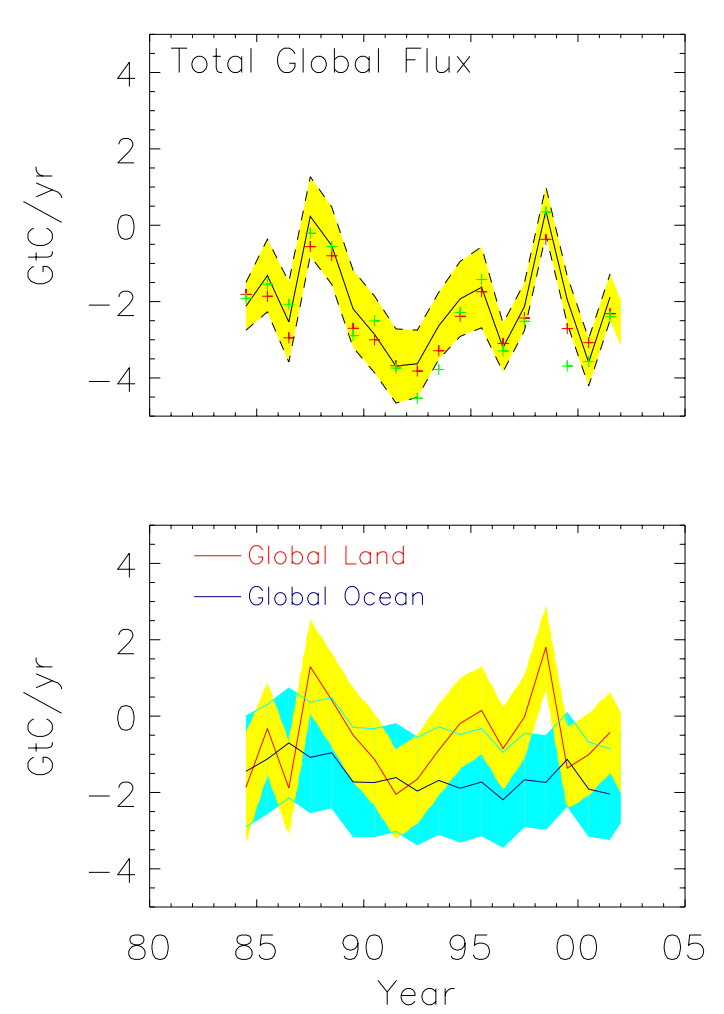

Fig. 3. (Top) The estimated annual total global carbon flux and uncertainty. The yellow region shows the $1 \sigma$ confidence bounds, and the red crosses show the estimated global carbon flux from the zonal average model of Tans et al. (1989) (courtesy of J. Miller and $\mathrm{T}$. Conway) The green crosses show the global $\mathrm{CO}_{2}$ growth rate estimated from the observed concentrations at network sites. (Bottom) Estimated global total land and ocean fluxes. The thick red line and yellow shaded area shows the global total estimated land flux and the estimated $1 \sigma$ confidence bounds, the thick dark blue line and light blue shaded area shows the global total ocean flux estimates and $1 \sigma$ confidence bounds.

include the first year of the estimates since about a half year is required for the inversion to adjust from initial conditions.

We also integrate our discussion of the flux estimates with the resolution kernel, since we consider the latter to be a useful tool in the interpretation of the flux estimates. The resolution kernel will be shown row by row, where the diagonal element of each row indicates how well the parameter is resolved, and the off diagonal elements give an indication of the degree to which parameters may be distinguished from each other. We consider values greater than 0.75 to be large, and less than 0.4 to be small in the discussion below.

\subsection{Carbon flux estimates at global scales}

The upper panel of Fig. 3 shows the estimated annual average global net carbon fluxes aggregated from 22 source regions. Although we have used the time-dependent network construction described in the previous section, differences due to network configuration are small and well within the estimated errors. The $1 \sigma$ confidence interval decreases substantially as the network size increases over time, ranging from just under $1.0 \mathrm{GtC} \mathrm{yr}^{-1}$ to about $0.5 \mathrm{GtC} \mathrm{yr}^{-1}$. The net global fluxes vary considerably, ranging from nearly zero uptake in 1987 and 1998 to uptake of more than $3.0 \mathrm{GtC} \mathrm{yr}^{-1}$ during the early 1990's. Previous studies have suggested a connection between El Niño/ENSO and reductions in carbon uptake by the biosphere and oceans (e.g. Conway et al., 1994; Feely et al., 1999, 2002; Keeling et al., 1995; Rayner and Law, 1999; Rödenbeck et al., 2003a; Patra et al., 2005). As shown in Fig. 3, the estimated global uptake of $\mathrm{CO}_{2}$ was nearly zero during the strong El Niño's of 1987 and 1998. The early 1990's were also a period of positive ENSO index (Wolter and Timlin, 1993, 1998); however, cooler and wetter conditions due to the major Pinatubo volcanic eruption likely caused the increased uptake during the early 1990's, and may have also affected the response of the carbon cycle to the El Niño during this period (Conway et al., 1994; Ciais et al., 1995). The flux anomalies associated with the 1997/1998 El Niño shown in this study agree well with those of Rödenbeck et al. (2003a), Bousquet et al. (2000), Gurney et al. (2008), and Rayner et al. (1999) although they are smaller than those reported by Patra et al. (2005).

Figure 3 also shows global total fluxes calculated with the zonal average model described by Tans et al. (1989) (red crosses, upper panel). This flux estimation procedure does not use prior flux estimates. The zonal average model uses only zonally averaged observations and transport to infer the carbon fluxes. The agreement between the flux estimates from this study and the zonal average technique is very good, which is expected since both calculations use the same observations, and therefore must recover the same global growth rate. However, comparing the two different calculations provides a useful check on the overall consistency of the flux estimates. Flux estimates can fail to match the zonal average model global total fluxes if, for example, the solution is very tightly constrained to match the prior flux estimates. Also shown are the global growth rates of $\mathrm{CO}_{2}$ estimated directly from the observed concentrations at network sites. With the exception of a few years, the agreement is quite good, even though there are errors associated with calculating the global growth rate directly from observations that are mostly at the surface. A comparison to observed global growth of atmospheric $\mathrm{CO}_{2}$ was also done by Rayner et al. (2005) for their assimilation system that optimizes terrestrial biosphere model parameters. They found general agreement with the timing of estimated growth anomalies with differences in magnitudes that they attributed to the lack of biomass burning in their terrestrial biosphere model. Comparisons to global growth of atmospheric flux can be a valuable diagnostic for atmospheric inversions.

The global partition between the annual ocean and terrestrial biosphere flux estimates is shown in the lower part of Fig. 3. With the exception of large anomalies, such as the 

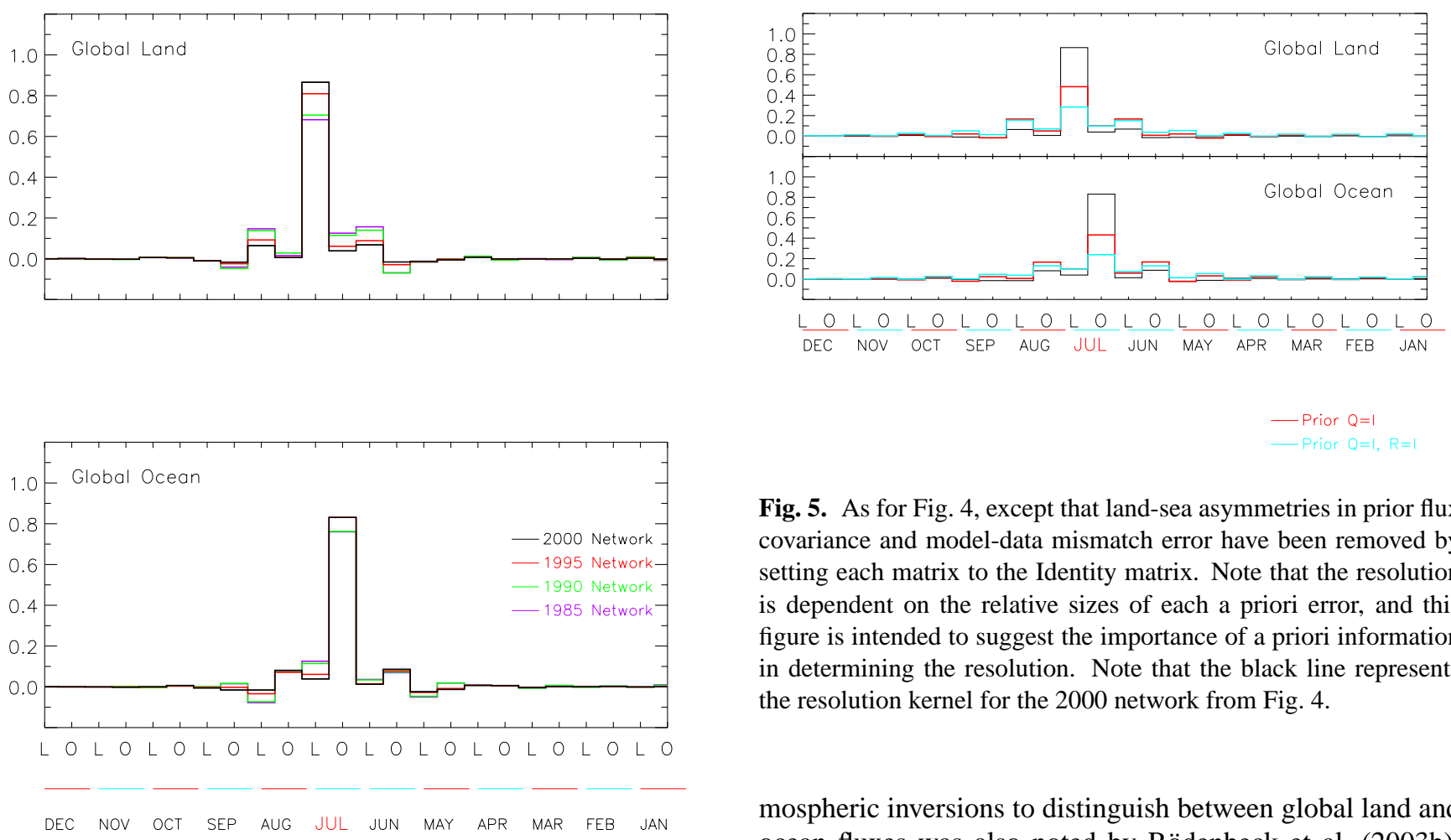

Fig. 5. As for Fig. 4, except that land-sea asymmetries in prior flux covariance and model-data mismatch error have been removed by setting each matrix to the Identity matrix. Note that the resolution is dependent on the relative sizes of each a priori error, and this figure is intended to suggest the importance of a priori information in determining the resolution. Note that the black line represents the resolution kernel for the 2000 network from Fig. 4.

Fig. 4. The resolution kernel for the global land and oceans in July calculated by aggregating monthly average basis functions, prior flux uncertainties, and mismatch error to global scales. Note that the resolution kernel shows how well the global land and oceans are resolved relative to each other within a particular month, as well as the degree to which the estimate for July is confused with the estimates for global ocean and land regions from previous and successive months. The " $\mathrm{L}$ " and "O" on the horizontal axis denote land and ocean regions for the month of interest and for adjacent time steps.

1998 El Niño, the $1 \sigma$ confidence intervals for the annual terrestrial biosphere and ocean fluxes overlap. It is questionable whether there is enough spatial information such that the inversion can tell global land and ocean sources apart. Although the appropriate cross terms of the covariance matrix could provide insight, we show the average resolution kernel (Fig. 4), obtained by calculating the resolution kernel using aggregated response function, prior flux uncertainty and model-data mismatch error matrices. Figure 4 shows that the global partitioning between land and ocean fluxes is resolvable using even early networks (implying the latter possibility) where values of the diagonal element reach at least 0.7. There is little tendency for the solutions for the global oceans and biosphere to be confused either within a particular month, or between adjacent months since the off-diagonal elements of the resolution kernel are very small; less than 0.2. The inversion is able to better distinguish the global total ocean and land fluxes as the network expands, especially for Northern Continental regions. The ability of at-

mospheric inversions to distinguish between global land and ocean fluxes was also noted by Rödenbeck et al. (2003b). They obtained similar land/ocean partitioning even when different prior fluxes were used.

It is important to recognize that the relative sizes of the global land and ocean prior flux uncertainties and the larger model-data mismatch errors for continental sites play an important role in the ability to distinguish global land and ocean fluxes. This may be seen from Fig. 5, where land-sea asymmetries in these quantities are eliminated from both the prior flux covariance and the model-data mismatch errors by using the same values for both ocean and land. Although the resolution of global ocean and land fluxes is also dependent on the relative sizes of the prior flux covariance and modeldata mismatch error, this figure illustrates the importance of a priori information and how it contributes to the spatial distribution of estimated fluxes. The a priori error estimates of ocean carbon fluxes are usually much smaller than prior terrestrial flux error estimates, and this plays a significant role in constraining the optimization.

As for the global net flux, the $1 \sigma$ confidence interval for the global annual terrestrial biosphere flux estimate decreases from a maximum of about $1.5 \mathrm{GtC} \mathrm{yr}^{-1}$ to about $1.0 \mathrm{GtC} \mathrm{yr}^{-1}$ with increasing network coverage (Fig. 3b). In contrast, the uncertainty for the global annual ocean fluxes is only slightly reduced over time. This is because many recently added sites sample continental regions, while the number of observations constraining the oceans has increased more slowly. Also, since the terrestrial fluxes are often much larger than the ocean fluxes, continental sites cannot provide reliable information on ocean fluxes. Differences in the global annual land and ocean fluxes due to changes in the 
Table 2. Comparison of 1992-1996 Average Carbon Fluxes Estimated by This Study and Those of Baker et al. (2006), Gurney et al. (2004), Jacobson et al. (2007) and Rödenbeck et al. (2003a). The numbers in the parentheses are estimated uncertainties.

\begin{tabular}{lrrrrr}
\hline & This Study & Baker & Gurney & Jacobson & Rodenbeck \\
\hline Global & $-2.6(0.6)$ & $-3.3(0.2)$ & $-2.8(.0)$ & $-2.8(0.1)$ & $-3.5(0.1)$ \\
Global Prior & $-1.7(1.9)$ & $-1.2(2.8)$ & $-1.2(2.8)$ & $\mathrm{NA}$ & $-2.3(2.9)$ \\
Land & $-0.7(1.1)$ & $-2.3(0.5)$ & $-1.5(1.0)$ & $-1.1(0.2)$ & $-1.8(0.4)$ \\
Land Prior & $-0.1(1.9)$ & $0.9(2.6)$ & $0.9(2.6)$ & $\mathrm{NA}$ & $-0.5(2.7)$ \\
Ocean & $-1.9(1.4)$ & $-1.0(0.5)$ & $-1.3(1.0)$ & $-1.7(0.2)$ & $-1.7(0.3)$ \\
Ocean Prior & $-1.6(0.4)$ & $-2.1(0.9)$ & $-2.1(0.9)$ & $\mathrm{NA}$ & $-1.8(1.0)$ \\
Northern Land & $-2.3(0.7)$ & $-2.7(0.3)$ & $-2.4(1.1)$ & $-2.9(1.0)$ & $-0.5(0.2)$ \\
Northern Oceans & $-1.0(0.7)$ & $-1.0(0.2)$ & $-0.9(0.6)$ & $-1.1(0.1)$ & $-1.6(0.2)$ \\
Tropical Land & $0.6(1.1)$ & $1.6(0.7)$ & $1.8(1.8)$ & $4.2(2.7)$ & $-1.2(0.3)$ \\
Tropical Oceans & $0.3(0.7)$ & $0.6(0.3)$ & $0.0(0.6)$ & $0.8(0.1)$ & $0.9(0.2)$ \\
Southern Land & $1.0(1.1)$ & $-1.2(0.6)$ & $-0.8(1.2)$ & $-2.4(2.0)$ & $-0.1(0.2)$ \\
Southern Oceans & $-1.6(0.7)$ & $-0.6(0.3)$ & $-0.5(0.6)$ & $-1.4(0.1)$ & $-1.0(0.1)$ \\
\hline
\end{tabular}

network are slightly larger than for the global total annual fluxes, but are still well within the estimated $1 \sigma$ confidence intervals. The results shown here are consistent with those found by Gurney et al. (2008) and Patra et al. (2005) for the Transcom 3 ensemble of transport models. In their studies, they estimated fluxes for a variety of networks and found that global aggregated land and ocean fluxes are not very sensitive to network changes, a result that we confirm here.

The global land and ocean fluxes over the period 1994 to 2001 are in good agreement with estimates obtained using measurements of $\mathrm{O}_{2} / \mathrm{N}_{2}$ over the period 1994-2003 obtained by Bender et al. (2005). They find an average terrestrial uptake of $0.8-1.0 \pm 0.6 \mathrm{GtC} \mathrm{yr}^{-1}$ and an average ocean uptake of 1.7-2.1 \pm 0.5 , while aggregated estimates for this study are $0.7 \pm 1.0 \mathrm{GtC} \mathrm{yr}^{-1}$ and $-1.9 \pm 1.2 \mathrm{GtC} \mathrm{yr}^{-1}$. The interannual variability of the carbon fluxes estimated in this study, including the large terrestrial response to the $1998 \mathrm{El}$ Niño, are also comparable to the results of Bender et al. (2005), although we find less interannual variability for the ocean fluxes.

Table 2 shows a comparison of our global total, land and ocean fluxes with those published recently. The studies by Gurney et al. (2004) and Jacobson et al. (2007) use a global mass constraint derived from observations, and therefore agree with the observed global $\mathrm{CO}_{2}$ growth rate shown in Fig. 3 averaged over 1992 to $1996\left(2.8 \mathrm{GtC} \mathrm{yr}^{-1}\right)$. Our average global flux is slightly less than the observed value and this is consistent with the influence of the global prior flux, which is considerably smaller than the observed value due to a neutral biosphere. The results of Baker et al. (2006) and Rödenbeck et al. (2003a) show a much larger than observed global uptake of carbon. Baker et al. (2006) note that the global growth obtained from the observations they used were $0.3 \mathrm{GtC} \mathrm{yr}^{-1}$ smaller than that used by Gurney et al. (2004), and this along with slightly larger fossil fuel emissions accounts for the difference in the global fluxes. It is interesting that even for the global total flux, there can be significant differences between the flux estimates, and we note that all studies shown used the same fossil fuel inputs, albeit with small differences that my arise through interpolation.

The average global ocean fluxes shown in Table 2 may be grouped into two categories, with Baker et al. (2006) and Gurney et al. (2004) showing much less uptake by oceans than the other three studies. Not surprisingly, these studies show more uptake by the global terrestrial biosphere. Note that the joint inversion of Jacobson et al. (2007) and the study by Rödenbeck et al. (2003a) use ocean carbon measurements to constrain ocean fluxes, making the agreement between these calculations of ocean uptake very good.

\subsection{Zonal average carbon flux estimates}

The resolution kernel for the TransCom 3 source regions (grouped as shown in Table 3) aggregated to approximately zonal land regions is shown in Fig. 6. From this figure, it is clear that the zonal land regions are well resolved for the recent two networks (1995 and 2000) with diagonal elements of 0.8 or greater, but not as well for the earlier networks. Due to increased observational coverage in the 2000 network, the resolution of the High Northern Land regions is significantly increased and the fluxes for this region are wellresolved. The same is true in general for the other terrestrial regions as well, with steady improvement in resolution from adjacent ocean regions as the network expands. For the 1985 network, the Tropical Lands are unresolved with a diagonal elements of less than 0.4. For the Temperate Southern Lands, the fluxes from the land and adjacent ocean regions cannot be distinguished for the early networks since 
Table 3. Definition of Land and Ocean Zones (Numbers correspond to those used in the Figures).

\begin{tabular}{llll}
\hline Zone & TransCom 3 Region & & \\
\hline High N. Land (1) & Boreal N America (1) & Boreal Eurasia (7) & \\
Temperate N. Land (2) & Temp. N America (2) & Temp. Asia (8) & Europe (11) \\
Tropical Land (3) & Amazonia (3) & N. Africa (5) & SE Asia (9) \\
Temperate S. Land (4) & Temp. S America (4) & S Africa (6) & Australia (10) \\
High N. Oce. (5) & Northern Oce. (16) & & \\
Temperate N. Oce. (6) & N Pacific (12) & N Atlantic (17) & \\
Tropical Oce. (7) & W/E Eq. Pacific (13,14) & Eq. Atlantic (18) & Eq. Ind. Oce. (21) \\
Temperate S. Oce. (8) & S Pacific (15) & S Atlantic (19) & Temp.Ind. Oce. (22) \\
High Southern Oce. (9) & Southern Oce. (20) & & \\
\hline
\end{tabular}

they have corresponding peaks of less than 0.2. For the recent networks, the resolution of these regions is significantly improved. For the less well-sampled Tropical and Southern Hemisphere zones much of the inversion's ability to separate land and ocean fluxes comes from land-ocean asymmetries in prior flux uncertainty (as for the global land-sea flux partitioning).

The aggregated zonal land flux estimates and uncertainties are shown in Fig. 7. Effects of changes in network configuration are evident at this spatial scale, particularly for the Temperate Northern Hemisphere Land where the number of observing sites has increased significantly with time. In contrast, the jumps are not as large for the Temperate Southern Hemisphere and Southern Ocean zones, where the number of observing sites has increased less. Note the decreases in the $1 \sigma$ confidence intervals for the Northern Hemisphere Land zones, and the small decrease in the tropical land zone. As the size of the network increases and the estimated error decreases, the estimates for ocean and land regions become more distinguishable.

As the number of sampling sites constraining the Temperate Land regions increases, the estimated carbon uptake increases significantly. This may imply that the earlier, sparser networks produce biases towards underestimation of uptake, but it is also possible that there are model biases relating to vertical mixing influence the inversion increasingly as more sites directly sample continental air. The increased uptake in the Northern temperate land zone occurs at the expense of uptake over the less well-constrained tropical land regions.

Figure 7 suggests that the large response to the $1998 \mathrm{El}$ Niño event occurred in tropical land regions where carbon was emitted to the atmosphere at a rate of about $2.0 \mathrm{GtC} \mathrm{yr}^{-1}$. This agrees well with the flux estimates of Rödenbeck et al. (2003a), Peylin et al. (2005), Rayner et al. (2008), Patra et al. (2005) and van der Werf et al. (2004), and with analyses that suggest warm, dry conditions over the tropics resulted in increased respiration and biomass burning (Zeng, 1999). It is interesting that for the 1987 El Niño no comparably large signal is found for the tropical land zone, however, there were fewer observations in the tropics during the 1980's, while more recently, shipboard observations and other sites have been added at low latitudes.

The resolution kernel for the zonal ocean regions (Fig. 8) shows that the Northern Hemisphere ocean zones are relatively well-resolved (diagonal elements greater than about 0.75) for the most recent networks, however, the diagonal elements for the Southern Hemisphere Ocean regions are closer to 0.6 . It is interesting that the inability to distinguish between the solution for a particular ocean region and an adjacent land region seems to be smaller than that between land and neighboring ocean regions. This is likely a result of the historical preference for locating network sites in the marine boundary layer in order to sample background atmospheric $\mathrm{CO}_{2}$ abundances.

Figures 6 and 8 suggest that for the 2000 network, and to a lesser extent, the 1995 network, the Equatorial and Southern Temperate Ocean and Land zones are fairly well-resolved. It is important to keep in mind, however, that the zonal estimates reflect the fluxes near to the (mostly surface) measurements. The zonal average flux for tropical land regions for example, does not include direct measurements of Tropical South America, and hence the response of the zonal average Tropical land fluxes to climate variability does not directly inform on the response of the ecosystems of Amazonia to such perturbations. Zonal (and global) aggregations are prone to errors and biases arising from the sparse underlying sampling distribution.

Table 2 shows a comparison with recent studies of 19921996 average flux results for Northern, Tropical and Southern land and ocean regions. All of the flux estimates show a consistent uptake over Northern land regions of more than $2 \mathrm{GtC} \mathrm{yr}^{-1}$ except for the results of Rödenbeck et al. (2003a) which are much smaller. The latter estimates use only 16 stations, and this may account for the differences from the other calculations. The fluxes for tropical and southern land regions vary much more, and this is a result of fewer observational constraints and more sensitivity to network choices and prior fluxes. 


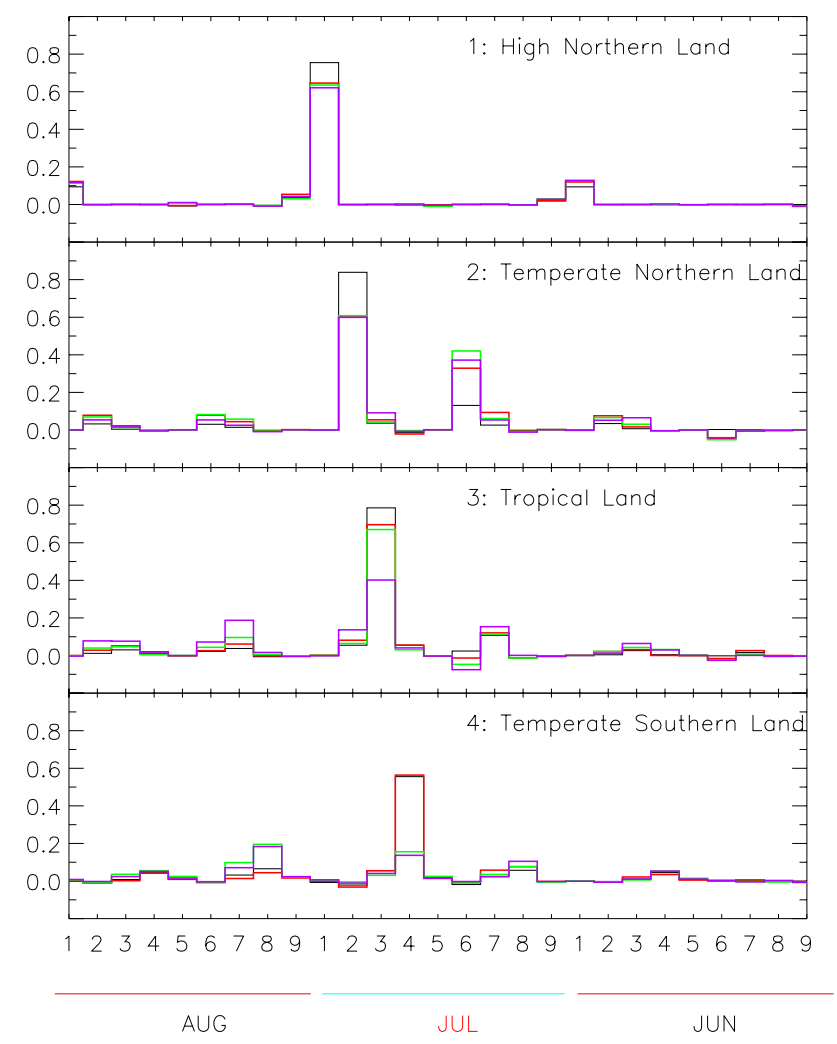

Fig. 6. The resolution kernel for approximately zonal land regions in July, calculated by aggregating monthly average basis functions, prior flux uncertainties, and mismatch error for the TransCom 3 regions. Note that the resolution kernel shows how well the zonal land regions are resolved within the month of July, as well as the degree to which the solutions for July are confused with solutions for zonal oceans and land from previous and successive months. The numbers on the horizontal axis indicate the zonal regions as follows: 1 - High Northern Land, 2 - Temperate Northern Land, 3 - Tropical Land, 4 - Temperate Southern Land, 5 - High Northern Ocean, 6 - Temperate Northern Oceans, 7 - Tropical Oceans, 8 - Temperate Southern Oceans, 9 - High Southern Ocean. Note also that the resolution kernel for the different networks as described in the text are shown: 2000 (black), 1995 (red), 1990 (green) and 1985 (purple).

It has recently been suggested by Stephens et al. (2007), using aircraft observations independent of flux inversions, that many of the models used to estimated carbon fluxes have transport biases that result in overestimated uptake by the terrestrial Northern Hemisphere and a corresponding overestimate of emissions by the terrestrial Tropics. They point out that the Transcom 3 Level 2 models that most closely match the annual observed $\mathrm{CO}_{2}$ profiles obtain flux estimates for the Northern Extra-Tropics and Tropical fluxes of $-1.5( \pm 0.6)$

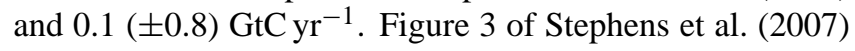
suggests that larger Northern uptake and Tropical emission are also (non-unique) solutions that agree with the observed vertical profile. In light of this, our average estimated uptake of $-2.3( \pm 0.7) \mathrm{GtC} \mathrm{yr}^{-1}$ for the Northern lands and 0.6

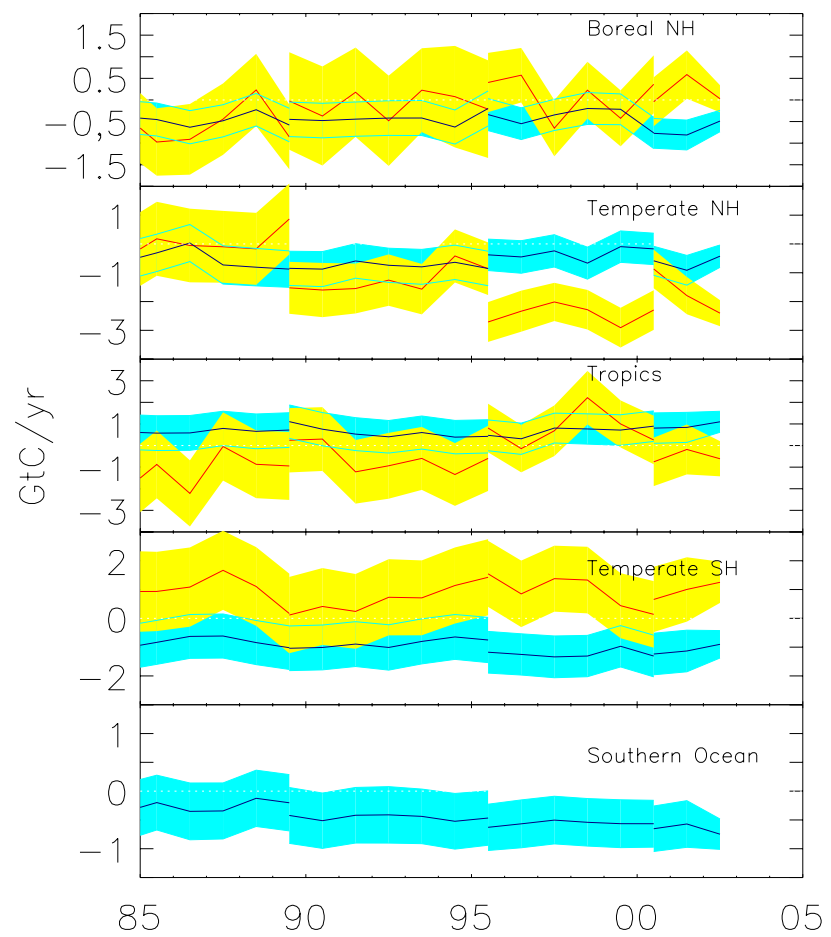

Fig. 7. Aggregated estimates of quasi-zonal land (red) and ocean (blue) fluxes. The shaded areas indicate the estimated $1 \sigma$ confidence bounds for the estimated land fluxes (yellow) and ocean fluxes (light blue). The jumps in the solution are the results of using time-varying networks as described in the text.

$( \pm 1.1){\mathrm{GtC} y r^{-1}}^{-1}$ for the Tropical lands are not necessarily inconsistent with the results of Stephens et al. (2007), however compensation by Southern land and ocean regions must also be considered.

The flux estimates for the Northern Oceans are similar for all of the studies in Table 2 except for Rödenbeck et al. (2003a) which shows more uptake, perhaps to compensate for less Northern land uptake. The range of the tropical ocean fluxes is quite large, with emissions ranging from 0

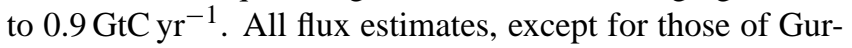
ney et al. (2004) agree to within the estimated errors with the estimate of Jacobson et al. (2007) which are constrained by ocean observations. On the other hand, only the estimates from this study agree with those of Jacobson et al. (2007) for the Southern oceans.

\subsection{Continental and ocean basin-scale carbon flux estimates}

In this section, we discuss flux estimates at continental and ocean basin-scales for the underlying source spatial resolution of 22 regions. As we will show, the ability to discern the spatiotemporal distribution of carbon fluxes is limited by the distribution of air samples in space and time. 


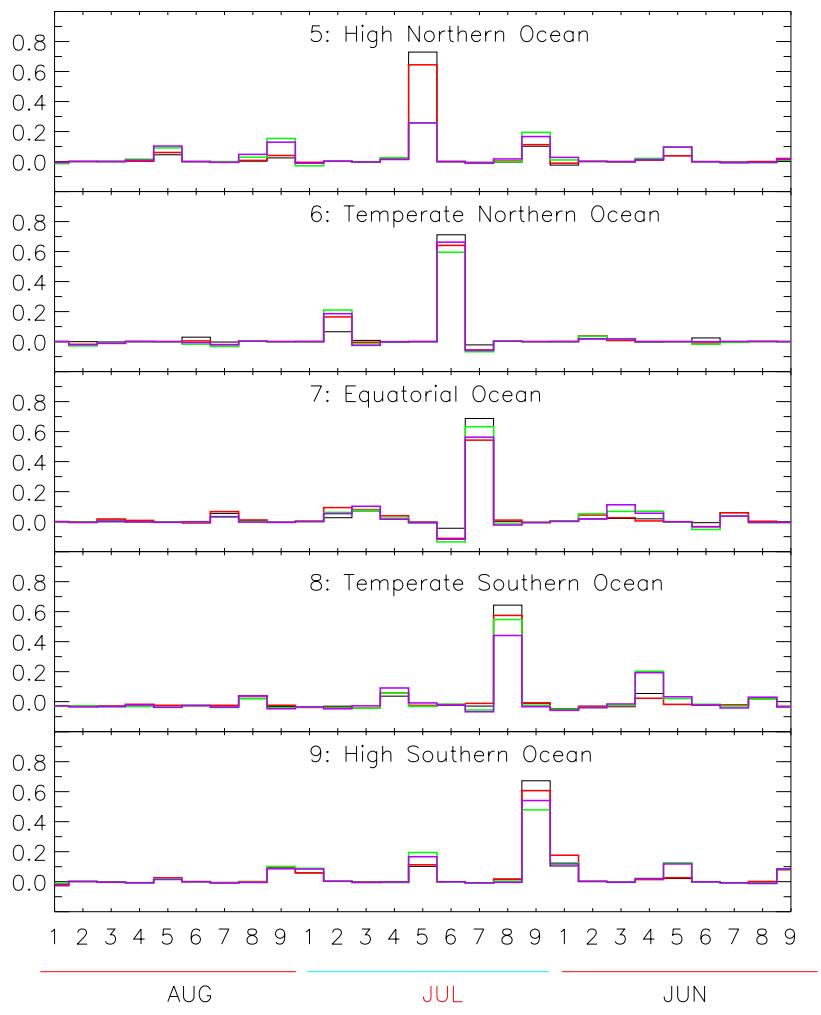

Fig. 8. The resolution kernel for approximately zonal ocean regions in July, calculated by aggregating monthly average basis functions, prior flux uncertainties, and mismatch error for the TransCom 3 regions. The numbers on the horizontal axis relate to the zonal regions as follows: 1 - High North Land, 2 - Temperate North Land, 3 Tropical Land, 4 - Temperate South Land, 5 - High North Ocean, 6 - Temperate North Oceans, 7 - Tropical Oceans, 8 - Temperate South Oceans, 9 - High South Ocean. Note also that the resolution kernel for the different networks as described in the text are shown: 2000 (black), 1995 (red), 1990 (green) and 1985 (purple).

The resolution kernel for the terrestrial TransCom 3 regions is shown in Fig. 9. Carbon fluxes estimated for Boreal and Temperate North America are readily distinguishable from the adjacent Northern Ocean and North Atlantic regions, although the diagonal elements have increased with network expansions from 0.6 or less to values of 0.8. For many regions, the resolution has substantially increased as the network has expanded. This is especially true for Australia, Europe and Southeast Asia where the diagonal values were initially 0.2 or less and have reached 0.75 or more for recent networks. On the other hand, source regions in South America, Africa and Boreal Eurasia are less well-resolved. In particular, South America is not resolved at all having diagonal values less than 0.2 , while North Africa is resolved to some extent for the 1995 and 2000 networks (diagonal values increasing from about 0.2 to 0.5 ), due to the addition of sites in Algeria and the Middle East. Southern Africa is generally not distinguishable from the Equatorial and South At-

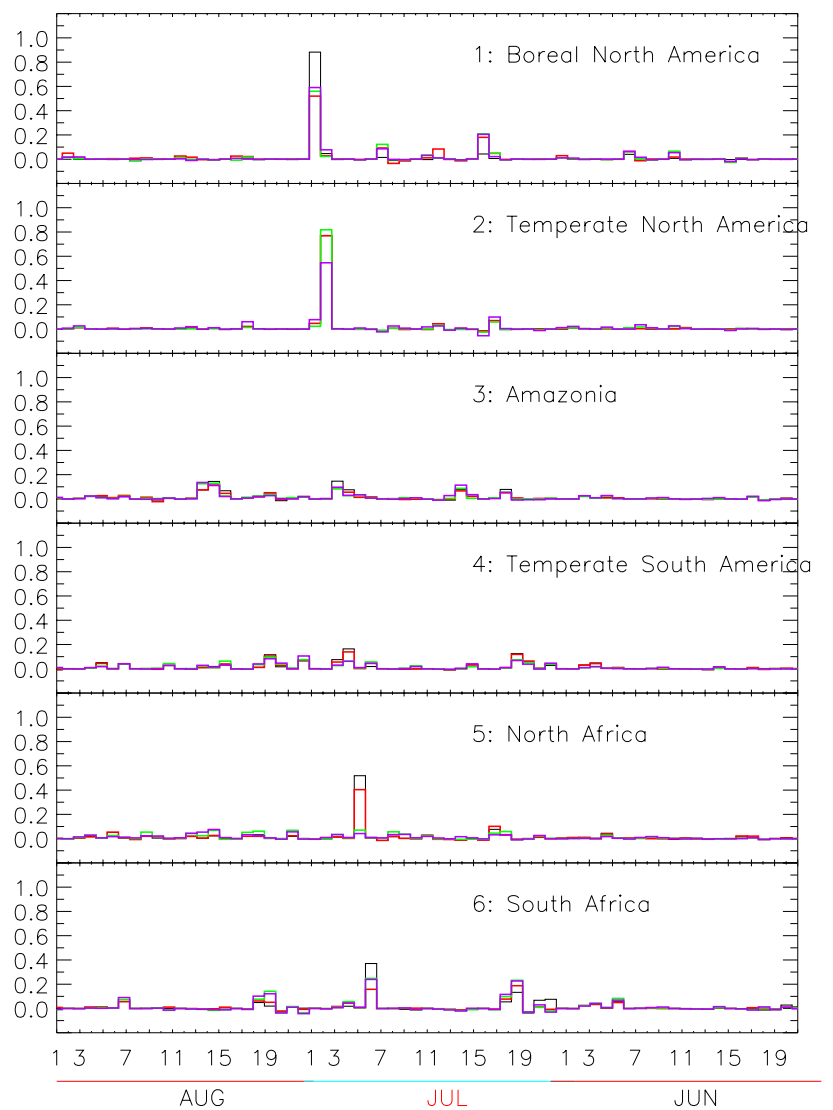

Fig. 9a. The resolution kernel for TransCom 3 terrestrial regions 1-6 in July. The numbers on the horizontal axis correspond to the individual TransCom regions as follows: 1 - Boreal North America, 2 - Temperate North America, 3 - Amazonia, 4 - Temperate South America, 5 - North Africa, 6 - South Africa. Note also that the resolution kernel for the different networks as described in the text are shown: 2000 (black), 1995 (red), 1990 (green) and 1985 (purple).

lantic ocean regions since the diagonal values and the peak corresponding to the South Atlantic are both about 0.4 and of comparable size. The ability to resolve Boreal Eurasian fluxes has increased slowly (going from 0.3 to 0.6 ), but the solution for this region is not entirely distinguishable from the adjacent Northern Ocean and North Pacific and Atlantic regions since there are corresponding peaks for these regions of about 0.2 .

There is an interesting contradiction between the resolution kernel calculated for zonal average source regions (shown in Fig. 6) and the resolution kernel calculated for individual tropical land regions. The zonal average resolution kernel suggests that the tropical land regions may be distinguished from tropical ocean regions. On the other hand, the resolution kernel calculated for continental scales implies that Amazonia and Northern Africa are not well-resolved. Southeast Asia is well-resolved however, and this accounts for the good resolution of zonal aggregations. The estimated 


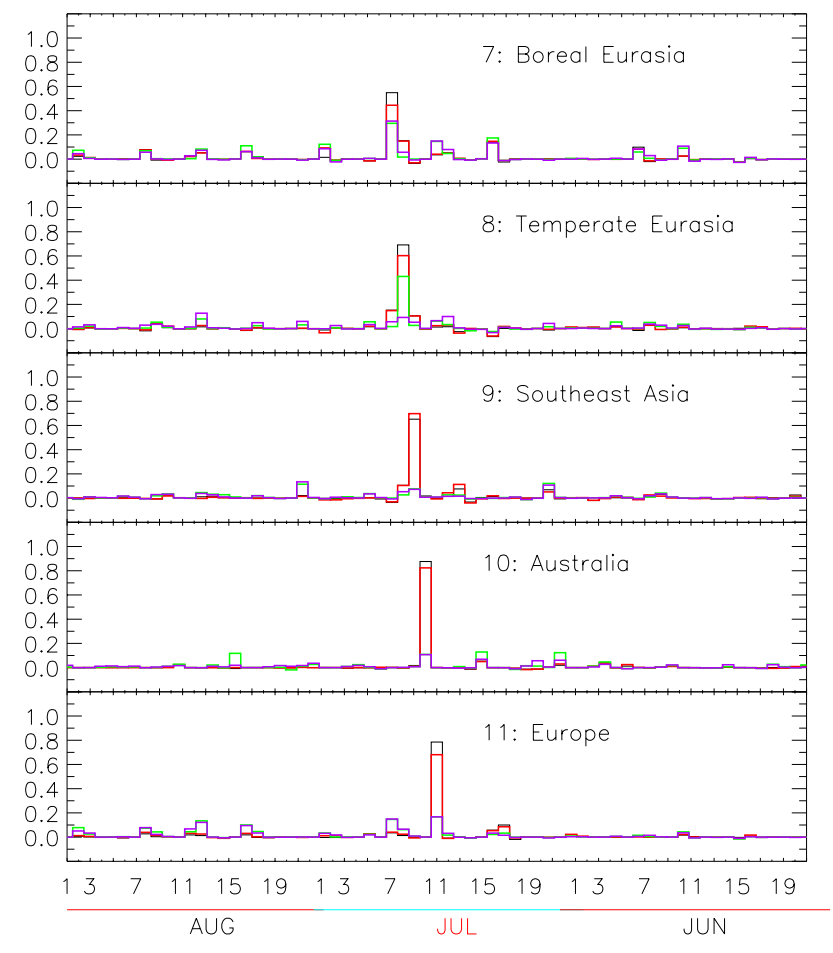

Fig. 9b. The resolution kernel for TransCom 3 terrestrial regions 7-11 in July. The numbers on the horizontal axis correspond to the individual TransCom regions as follows: 7 - Boreal Eurasia, 8 Temperate Eurasia, 9 - Southeast Asia, 10 - Australia, 11 - Europe. Note also that the resolution kernel for the different networks as described in the text are shown: 2000 (black), 1995 (red), 1990 (green) and 1985 (purple).

zonal average fluxes for the Tropical Land regions are a weighted combination of the observational constraints for Southeast Asia, and the prior flux estimates for other Tropical regions. It is therefore difficult to draw conclusions about responses of individual tropical land regions to large perturbations, such as the 1998 El Niño using even current networks.

Figure 10 shows the resulting annual average flux and uncertainty estimates for the 11 TransCom terrestrial regions. At High Northern latitudes, the abrupt changes in estimated fluxes due to changes in the network are evident, especially for Europe where the coverage has increased significantly in recent years. The estimated flux uncertainties decrease for all three High Northern latitude regions as the network expands in time. Note that although the estimated flux for Boreal North America remains relatively constant, ranging between about 0.0 and $0.5 \mathrm{GtC} \mathrm{yr}^{-1}$, there is a large rebalancing of uptake from Europe to Boreal Eurasia. The uptake of carbon for Europe decreases from greater than about $2 \mathrm{GtC} \mathrm{yr}^{-1}$ to an emission averaging about $0.5 \mathrm{GtC} \mathrm{yr}^{-1}$ from the late 1980's to the late 1990's, while the estimates for fluxes over Boreal Eurasia change from nearly a $1 \mathrm{GtC} \mathrm{yr}^{-1}$ source to about a $1 \mathrm{GtC} \mathrm{yr}^{-1}$ sink. It is somewhat surprising that Europe
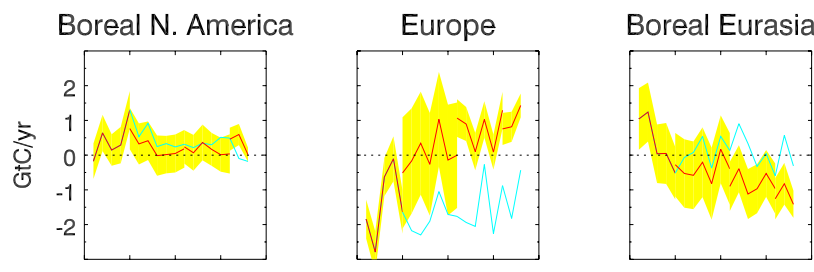

Temperate N. AmericaTemperate Eurasia
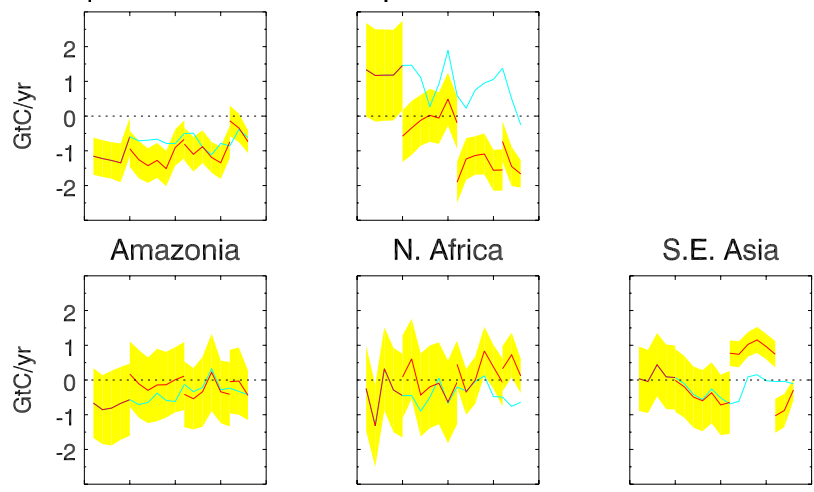

Temperate S. America

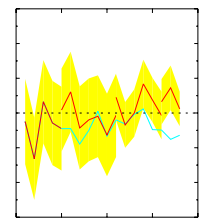

S. Africa
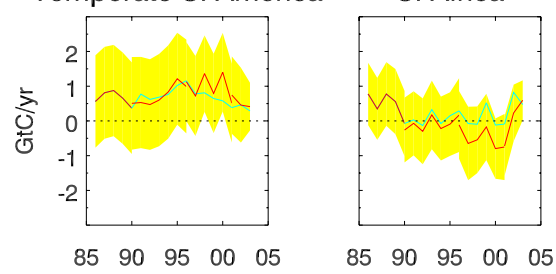

$\begin{array}{lllll}85 & 90 & 95 & 00 & 05\end{array}$

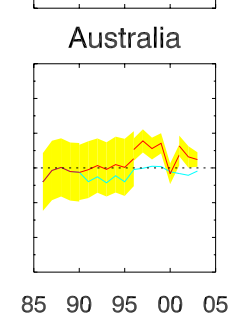

Fig. 10. Estimates of annual average terrestrial fluxes for the 11 TransCom 3 terrestrial source regions. The shaded yellow areas indicate the estimated $1 \sigma$ confidence bounds for the estimated fluxes. The blue curve show the flux estimates calculated using the 2000 network for the entire period.

appears to be a net source of non-fossil fuel carbon, however, the sites that most strongly constrain Europe (Baltic, Orleans and Bulgaria, for example) are likely located near local sources of fossil fuel emissions that are not correctly accounted for by the inversion ?a. One strategy to deal with this situation is to de-weight these data in the inversion, meaning in practice, that the newer continental observations are of less use in constraining fluxes. They should be used with care at the very least. Since Boreal Eurasia has the largest a priori flux uncertainty (and few observations to constrain it), this region is adjusted to compensate. Patra et al. (2006) also found sensitivity of estimated fluxes, particularly Europe, to use of continental sites, although they found increased uptake with inclusion of terrestrial sites rather than ocean sites only. Gurney et al. (2008) noted significant changes in flux estimates with changing networks, including a decrease in the European uptake for their 1995-2005 network. The details of how flux is distributed among source regions varies between the present study and previous work. These differences are determined by the relative weighting of model-data mismatch and prior flux uncertainties, as well as how the 
observations are used (e.g. time averaging or missing data criteria applied). However, the conclusion is that changing networks are likely to be a source of "noise" and uncertainty that must be considered when long time series of flux estimates are computed for the evaluation of trends. Furthermore, the unrealistic change in estimated fluxes underscores the care that must be taken when using difficult to model continental sites. It is possible to control fluctuations of flux estimates by tuning the model-data mismatch errors to dampen variations. The result would be greater influence of prior flux estimates and/or reduced spatial resolution of flux estimates. The best solution, as always, is better transport models and increased observational coverage.

Carbon flux estimates for Temperate North America have remained relatively constant over time at about $-1 \mathrm{GtC} \mathrm{yr}^{-1}$, however, the uptake of carbon for the 2000 network was greatly reduced by over half. Carbon uptake appears to be increasing towards $1 \mathrm{GtC} \mathrm{yr}^{-1}$ again during 2001 and 2002. Flux estimates calculated using the 2000 network (blue curve) shows smaller uptake over the entire period. These figures illustrate a fundamental difficulty in dealing with a sparse network that increases in resolution unevenly in space and slowly in time; it is difficult to attribute changes in estimated fluxes solely to biophysical processes unless sensitivity to network changes is considered as well.

As shown above, of the tropical land regions, only Southeast Asia is well-resolved, although the $1 \sigma$ confidence interval for North Africa is significantly reduced after the addition of a site in Northern Africa and one in the Middle East (namely, ASK and WIS). Southeast Asia appears to be a significant sink of carbon except for the period during the late 1990's when shipboard observations in the South China Sea were included in the estimation (the shipboard observations were discontinued and not included in the 2000 network). Although the quality of these shipboard data does not seem to be in question (Conway, personal communication), either their inclusion or exclusion appears to introduce a large bias in the calculation. It has been suggested by Arellano et al. (2004) and Petron et al. (2002) that the anthropogenic carbon monoxide (CO) emissions from Southeast Asia have been significantly underestimated, and this may be an explanation for why the biosphere in this region seems to become a large source when the South China Sea observations are included.

It is interesting that all tropical land regions show small decreases in uptake for 1998. The variations are small compared to changes due to network composition, and they are small compared to the $1 \sigma$ confidence intervals as well. Since Tropical Africa, Tropical South America, and sometimes, Southeast Asia cannot be distinguished from each other (and from adjacent ocean regions), it is likely that the $1998 \mathrm{El}$ Niño response is distributed in a somewhat even fashion over the tropical land regions.

Of the Temperate Southern Land regions, only Australia is well-resolved after about 1995. The flux estimates suggest that Australia is a small source of atmospheric carbon.

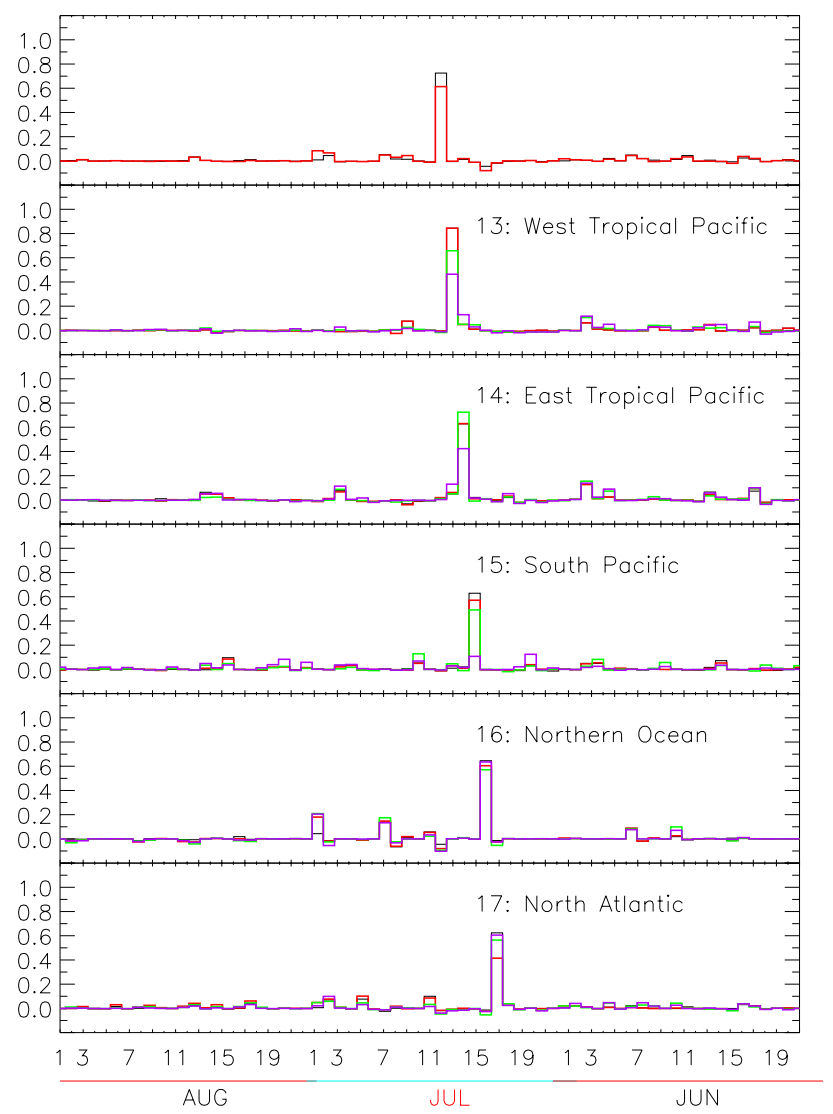

Fig. 11a. The resolution kernel for TransCom 3 ocean regions 1217 in July. The numbers on the horizontal axis correspond to the individual TransCom regions as follows: 12 - North Pacific, 13 Western Tropical Pacific, 14 - Eastern Tropical Pacific, 15 - South Pacific, 16 - Northern Ocean, 17 - North Atlantic. Note also that the resolution kernel for the different networks as described in the text are shown: 2000 (black), 1995 (red), 1990 (green) and 1985 (purple).

Estimated fluxes for Southern Africa and Temperate South America appear to roughly balance each other after 1995.

As shown in Fig. 11, the Pacific is generally well-resolved. The resolution is best for the North Pacific (diagonal elements of about 0.8 ), and has improved substantially for the Tropical and South Pacific for the two most recent networks (going from about 0.5 to greater than 0.75 ). The situation is quite different for the Atlantic Ocean. Although the North Atlantic is well-resolved by all networks (diagonal elements of about 0.75), the Equatorial and South Atlantic are not well-resolved (diagonal elements less than 0.6). The resolution of the South Atlantic is somewhat better than for the Equatorial Atlantic due to the sensitivity of the site at Ascension Island to air originating over the South Atlantic (even though Ascension Island is geographically located in the Equatorial Atlantic). 


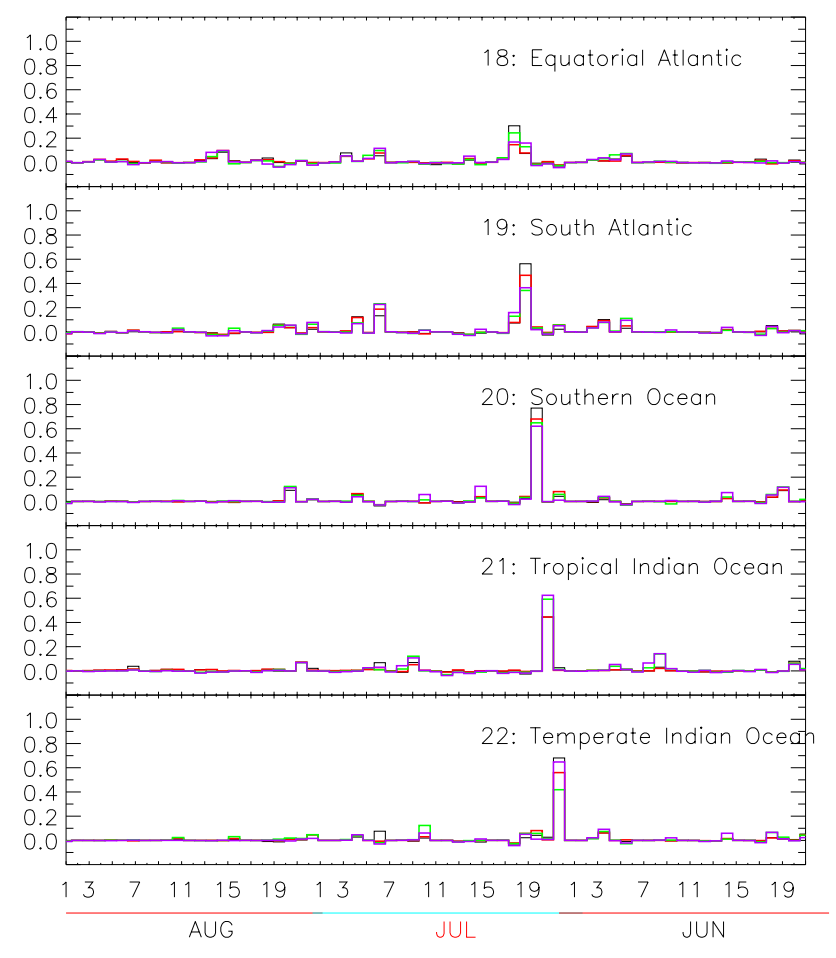

Fig. 11b. The resolution kernel for TransCom 3 ocean regions 1822 in July. The numbers on the horizontal axis correspond to the individual TransCom regions as follows: 18 - Equatorial Atlantic, 19 - South Atlantic, 20 - Southern Ocean, 21 - Tropical Indian Ocean, 22 - Temperate Indian Ocean. Note also that the resolution kernel for the different networks as described in the text are shown: 2000 (black), 1995 (red), 1990 (green) and 1985 (purple).

At high latitudes, the Southern Ocean is fairly wellresolved (with diagonal values greater than 0.75 for all networks) while the solution for the Northern Ocean has a diagonal element between 0.7 and 0.75 for all networks, with small (0.2) peaks indicating that the ability to distinguish the Northern Ocean from Boreal North America and Eurasia is somewhat limited. Note that there is a noticeable amount of "leakage" of signal between Boreal North America, Eurasia and the Northern Ocean as evidenced by peaks in the resolution kernels among these regions. On the other hand, the solutions for Temperate North America and Eurasia, and the Northern Atlantic and Pacific Oceans are more distinguishable.

Estimated fluxes and uncertainties for the TransCom ocean regions are shown in Fig. 12. The results are consistent with the idea that high latitude oceans are sinks of atmospheric carbon dioxide, while the tropical oceans are sources. Note that most ocean regions are sensitive to changes in network configuration. Regions with sparse observational coverage over the entire period are less sensitive to network changes over time. Examples are the Equatorial and South Atlantic and the Equatorial and Temperate Indian Oceans.
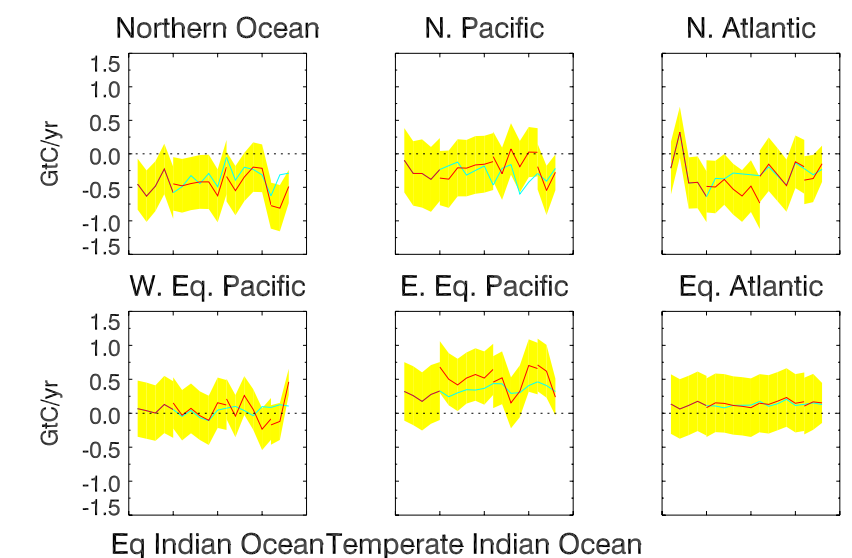

Eq. Atlantic
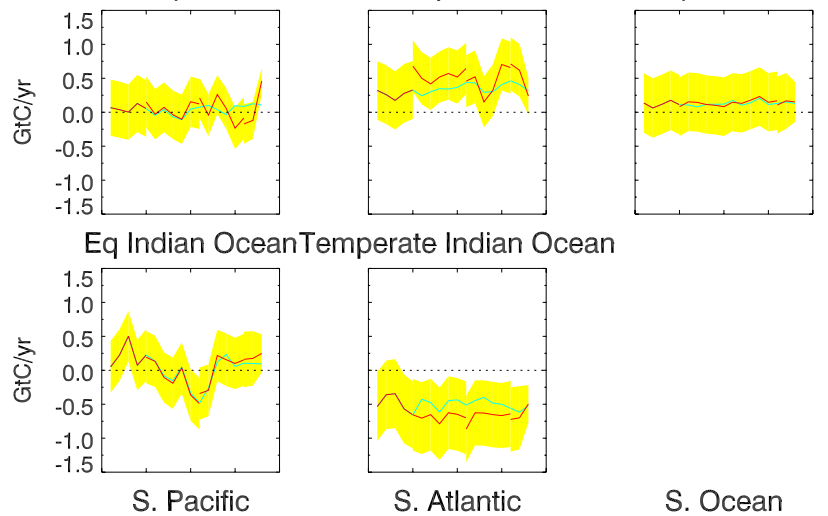

S. Atlantic
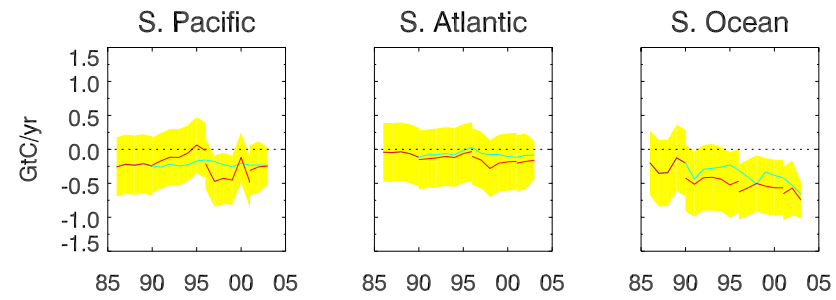

Fig. 12. Estimates of annual average ocean fluxes for the 11 TransCom 3 ocean source regions. The shaded yellow areas indicate the estimated $1 \sigma$ confidence bounds for the estimated fluxes. The blue curve show the flux estimates calculated using the 2000 network for the entire period.

Significant estimated uptake occurs over the Northern Ocean, North Atlantic and the Southern Ocean. Tans et al. (1990) and, more recently, Gurney et al. (2002) have pointed out that all of the models used in the TransCom 3 model intercomparison suggested that the Takahashi et al. (1999) ocean flux data used as a prior for the inversions are too high for the Southern Ocean by a factor of two, possibly due to a seasonal bias in the delta $p \mathrm{CO}_{2}$ measurements. Our results are consistent with their findings, showing uptake of about $0.5 \mathrm{GtC} \mathrm{yr}^{-1}$ for the Southern Ocean.

The largest estimated oceanic source of atmospheric carbon is found over the Eastern Equatorial Pacific and appears to be about $0.5 \mathrm{GtC} \mathrm{yr}^{-1} \pm 0.5 \mathrm{GtC} \mathrm{yr}^{-1}$. It is noteworthy that the flux from this region is at a minimum during 1997 and 1998, the time of a particularly strong El Niño. The results of Rayner et al. (2008) also show negative flux anomaly in the Tropical Pacific during this period, however, they note that the correlation between the Southern Oscillation Index and their estimated fluxes is not very robust. On the other hand, it is not clear that a similar feature exists for the El Niño of the late 1980's, although the network may have been too sparse in the late 1980's to resolve any perturbation. 


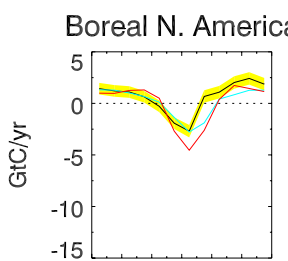

Temp. N. America

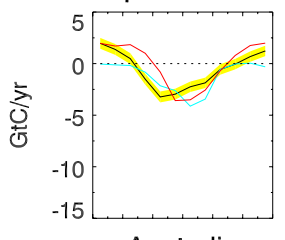

Australia

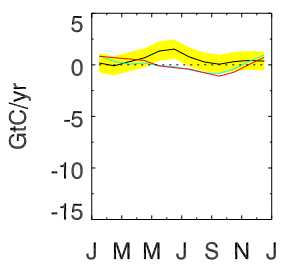

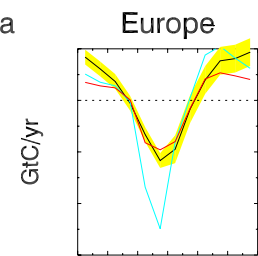

Temp. Eurasia

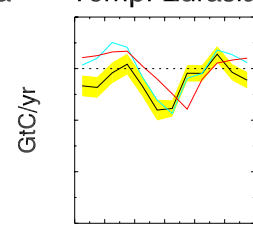

$J M M J S N$

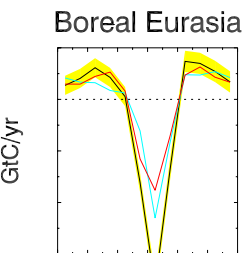

S.E. Asia

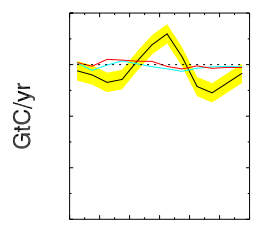

JMM J S N J
Fig. 13. Average seasonal cycles of estimated flux and uncertainty for the well-resolved TransCom 3 terrestrial source regions (plus Boreal Eurasia, which is not well-resolved).The black lines and shaded yellow areas indicate the estimated fluxes and $1 \sigma$ confidence bounds using the 2000 network. The red line is the prior flux estimate taken from the CASA model and the blue line shows flux estimates calculated using the 1990 network.

The average seasonal cycles of estimated and prior terrestrial fluxes using the 2000 network are shown in Fig. 13. For Boreal North America, the estimates suggest a more shallow summertime uptake than the prior flux estimates, with a more gradual onset of summertime uptake. For Europe, the flux estimates suggest more emission to the atmosphere during the winter and slightly more uptake than the prior flux estimate. The flux estimates for Boreal Eurasia revise the prior flux significantly, increasing the uptake during the growing season by almost a factor of two. Note that the prior flux estimate is balanced annually and may underestimate the true uptake. Although the results of Gurney et al. (2004) also show a larger estimated summertime uptake for Boreal Eurasia than the prior flux estimate, the results shown in Figure 13 differ from the results of Gurney et al. (2004) in that the winter respiration fluxes are little changed from the prior, while the uptake during the growing season is significantly larger than the prior estimates. Figures 9 and 11 suggest that Boreal Eurasia is the least distinguishable region at high Northern latitudes, and the large increases in uptake are likely the result of the high prior flux uncertainty for this region. It is also interesting that the peak carbon uptake estimated by Gurney et al. (2004) is distributed more evenly between Europe and Boreal Eurasia, whereas our results show less European uptake and more for Boreal Eurasia. This difference is due to our use of more observation sites, since the partitioning of flux between these two regions is very dependent on network composition. Model transport biases may also play a role in the adjustment towards less summer uptake for Europe.

In the Temperate Northern Hemisphere, the flux estimates suggest that the summer uptake occurs earlier than it does for the prior fluxes by about a month for the most recent network. For the more sparse 1990 network, the timing of the summer uptake occurs later than for the prior. In the case of Temperate Eurasia, the timing of the summertime uptake is also shifted earlier, especially for the more recent network. Less carbon emission during the Northern Hemisphere winter is estimated for both Temperate North America and Temperate Eurasia (for the 2000 network), and the latter is a carbon sink throughout most of the year

The only tropical terrestrial source region that is wellresolved is Southeast Asia, where the inverse flux estimates for the 2000 network suggest considerable seasonality while the prior flux estimate is rather flat. A peak in emissions occurs during the Northern Hemisphere summer, and the seasonality of the flux estimates is likely related to the Asian summer monsoon cycle.

Temperate South American flux estimates are not significantly changed from the prior flux estimate due to the lack of observations to constrain this region. On the other hand, the seasonality suggested by the prior flux estimates for Southern Africa are discarded by the inversion, which produces a rather flat seasonal cycle centered around zero instead. Note that the resolution kernel for this region suggest some confusion with the estimated flux for the adjacent South Atlantic. The flux estimates for Australia (which is well-resolved for the 2000 network and not resolved for the 1990 network) are also interesting, since they imply a net positive flux of carbon dioxide to the atmosphere, with a peak in emissions occurring during Austral Autumn for the recent network. The prior and 1990 network flux estimates, on the other hand, show small uptake of carbon over the Austral winter that peaks in early Austral spring.

Figure 14, the average annual cycles for well-resolved ocean regions, shows that the amplitude of the seasonal cycle for the Northern Ocean, North Pacific, North Atlantic, and Western Equatorial Pacific are all significantly increased relative to the prior ocean flux estimate. Gurney et al. (2004) and Peylin et al. (2005) have suggested that these results are due to the inability of the transport model and flux estimation procedure to distinguish between signals coming from adjacent ocean and land regions. The resolution kernel, to the contrary, shows that, with the exception of the Northern Ocean, these ocean regions are distinguishable. Only the seasonality of the North Atlantic tends to be roughly in phase with the adjacent upstream continental region. The sites constraining this region are all marine sites such as the Canary Islands, Bermuda and the Azores. These sites sit within the summertime high pressure that forms over the Atlantic. A larger estimated uptake of carbon over this region implies 


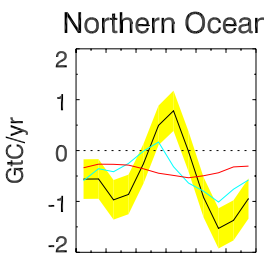

W. Eq. Pacific

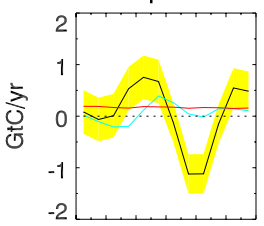

S. Pacific

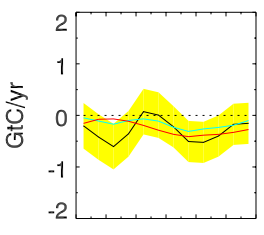

J M M J S N

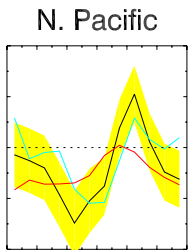

E. Eq. Pacific

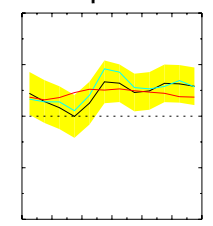

Temp. Indian Ocean

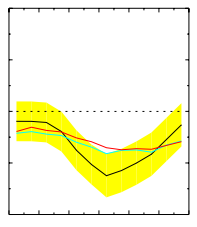

JMM J S N J

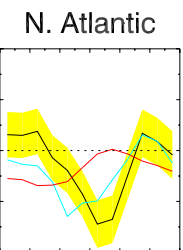

Eq Indian Ocean

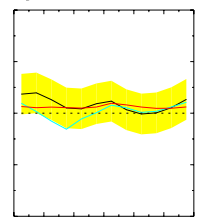

S. Ocean

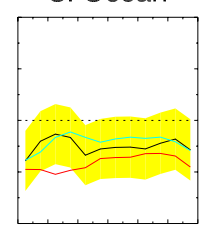

JMM J S N J
Fig. 14. Average seasonal cycles of estimated flux and uncertainty for the well-resolved TransCom 3 ocean source regions. The black lines and shaded yellow areas indicate the estimated fluxes and $1 \sigma$ confidence bounds for the 2000 network. The red line is the prior flux estimate taken from Takahashi et al. (1999), and the blue line shows the flux estimates using the 1990 network. Note the change in scale from Fig. 13.

that the predicted carbon abundance is systematically higher than observed. This could arise as a result of a bias towards unrealistically weak vertical mixing over continents, which would result in higher carbon abundance aloft and in the air subsiding from the mid-troposphere over the summertime Atlantic. Similar transport biases likely produce the large seasonal variations over other ocean regions.

\section{Conclusions}

This study has explored the extent to which ESRL-GMD's current global observational network may be used to characterize carbon fluxes at various spatial and temporal scales. Spatial and temporal resolution was evaluated using the resolution kernel, while bias due to limited sampling coverage was considered by allowing the network to change over time as more sites were added. Inversions were performed using the TM3 atmospheric tracer model, and a fixed-lag Kalman smoother technique.

At global spatial scales, the partition between ocean and land fluxes is distinguishable, even for the extremely sparse network of the late 1980's. Shifts in the estimated fluxes for the global oceans and terrestrial biosphere due to the expansion of the observational network are well within the esti- mated uncertainties, but still are large enough to mask small trends over the period of these calculations.

Changes in the distribution of inferred zonal fluxes due to observational network expansion are significant and can exceed estimated flux uncertainties. In particular, a redistribution of carbon flux occurs between the Temperate and Tropical land zones with time, with increases in uptake for the Temperate land zone and decreases for the Tropical land zone. Spatial resolution increases as the network expands, and even in the tropics, the zonal land and oceans may be distinguished for recent networks, although the zonal fluxes may not represent the true zonal averages due to uneven distribution of samples. Tropical Asia is well-constrained by observations, for example, while Tropical South America is essentially unconstrained. The zonal average in this case reflects the influence of the prior flux estimates for unconstrained tropical land regions, and interannual variability may be underestimated and misallocated. Significant interannual variability is estimated for the well-constrained Northern land regions.

The attribution of long-term trends among the various zones and analysis of interannual variability is problematic due to network changes. Evaluation of the resolution kernel suggests that consideration of only a small set of sites in continual operation over the entire time period results in reduced spatial resolution. The inversion is unable to distinguish between High Latitude land and ocean regions or between Tropical lands and oceans. The ability to detect changes in carbon fluxes over the last $25 \mathrm{yr}$ is effectively limited to significant changes in the global total land and ocean fluxes due to the sparseness and changing distribution of the observational network. Furthermore, use of extremely sparse networks with long records will likely not be able to spatially attribute atmospheric trends very well.

Flux estimates at continental and zonal scales appear to be very sensitive to network changes, and in some cases large re-distributions occur between regions over time. An example is the large decrease of carbon uptake over time for Europe and the concurrent large increase for Boreal Eurasia. Changes in estimated fluxes over multiple decades are therefore difficult to interpret, and the ability to detect and track long-term trends in fluxes at regional scales is likely limited by network changes. On the other hand, spatial resolution for many regions has significantly increased over time, especially for Australia, Europe and Southeast Asia. A caveat is that the new, mostly continental sites must be used with care by possibly de-weighting them in the inversions due to the possibility of unresolved local sources. Even though the estimates have tighter confidence bounds, the solution may still be biased. Tropical and Temperate regions in South America and Africa remain relatively unresolved, as does Boreal North America and the Equatorial and South Atlantic. However, the partition of carbon fluxes between land and adjacent ocean regions is possible for well-sampled regions such as Temperate North America and Europe. 
Acknowledgements. The authors wish to thank Gabrielle Petron, Andy Jacobson, Rachel Law and anonymous reviewers for their helpful comments. This work was supported by the National Oceanic and Atmospheric Administration, Earth System Research Laboratory.

Edited by: C. Heinze

\section{References}

Andres, R. J., Marland, G., Fung, I., and Matthews, E.: A 1 degrees $\times 1$ degrees distribution of carbon dioxide emissions from fossil fuel consumption and cement manufacture, 1950-1990, Global Biogeochem. Cy., 10, 419-429, 1996.

Arellano, A. F., Kasibhatla, P. S., Giglio, L., van der Werf, G. R., and Randerson, J. T.: Top-down estimates of global CO sources using MOPITT measurements, Geophys. Res. Lett., 31, L01105 doi:10.1029/2003GL018678, 2004.

Backus, G. and Gilbert, F.: Uniqueness in the inversion of inaccurate gross earth data, Philos. T. R. Soc. S.-A, 266, 123-192, 1970.

Baker, D., Law, R., Gurney, K., Rayner, P., Peylin, P., Denning, A., Bousquet, P., Bruhwiler, L., Chen, Y.-H., Ciais, P., Fung, I., Heimann, M., John, J., Maki, T., Maksyutov, S., Masarie, K., Prather, M., Pak, B., Taguchi, S., and Zhu, Z.: TransCom 3 inversion intercomparison: Impact of transport model errors on the interannual variability of regional $\mathrm{CO}_{2}$ fluxes, 1988-2003, Global Biogeochem. Cy., 20, GB1002 doi:10.1029/2004GB002439, 2006.

Bender, M., Ho, D. T., Hendricks, M. B., Mika, R., Battle, M. O., Tans, P. P., Conway, T. J., Sturtevant, B., and Cassar, N.: Atmospheric $\mathrm{O}_{2} / \mathrm{N}_{2}$ changes, 1993-2002: Implications for the partitioning of fossil fuel $\mathrm{CO}_{2}$ sequestration, Global Biogeochem. Cy., 19, GB4017 doi:10.1029/2004GB002410, 2005.

Bousquet, P., Peylin, P., Ciais, P., Le Quere, C., Friedlingstein, P., and Tans, P. P.: Regional changes in carbon dioxide fluxes of land and oceans since 1980, Science, 290, 1342-1346, 2000.

Brenkert, A.: Carbon dioxide emission estimates from fossil-fuel burning, hydraulic cement production, and gas flaring for 1995 on a one degree grid cell basis, Tech. Rep. NDP-058A, Carbon Dioxide Information Analysis Center, 1998.

Bruhwiler, L. M. P., Michalak, A. M., Peters, W., Baker, D. F., and Tans, P.: An improved Kalman Smoother for atmospheric inversions, Atmos. Chem. Phys., 5, 2691-2702, doi:10.5194/acp-52691-2005, 2005.

Chevallier, F.: Impact of correlated observation errors on inverted $\mathrm{CO}_{2}$ surface fluxes from OCO measurements, Geophys. Res. Lett., 34, L24804, doi:10.1029/2007GL030463, 2007.

Chevallier, F., Viovy, N., Reichstein, M., and Ciais, P.: On the assignment of prior errors in Bayesian inversions of $\mathrm{CO}_{2}$ surface fluxes, Geophys. Res. Lett., 33, L13802, doi:10.1029/2006GL026496, 2006.

Ciais, P., Tans, P. P., Trolier, M., White, J. W. C., and Francey, R. J.: A Large Northern-Hemisphere Terrestrial $\mathrm{Co}_{2}$ Sink Indicated by the C-13/C-12 Ratio of Atmospheric $\mathrm{Co}_{2}$, Science, 269, 10981102,1995

Conway, T. J., Tans, P. P., Waterman, L. S., and Thoning, K. W.: Evidence for Interannual Variability of the Carbon-Cycle from the National-Oceanic-and-Atmospheric-Administration
Climate-Monitoring-and-Diagnostics-Laboratory Global-AirSampling-Network, J. Geophys. Res.-Atmos., 99, 22831-22855, 1994.

Denning, A. S., Holzer, M., Gurney, K. R., Heimann, M., Law, R. M., Rayner, P. J., Fung, I. Y., Fan, S. M., Taguchi, S., Friedlingstein, P., Balkanski, Y., Taylor, J., Maiss, M., and Levin, I.: Three-dimensional transport and concentration of SF6 - A model intercomparison study (TransCom 2), Tellus B, 51, 266297, 1999.

Engelen, R., Denning, A. S., Gurney, K. R., and Modelers, T.: On error estimation in atmospheric $\mathrm{CO}_{2}$ inversions, J. Geophys. Res.-Atmos., 107, 4635, doi:10.1029/2002JD002195, 2002.

Enting, I. G., Trudinger, C. M., and Francey, R. J.: A Synthesis Inversion of the Concentration and Delta-C-13 of Atmospheric $\mathrm{Co}_{2}$, Tellus B, 47, 35-52, 1995.

Fan, S., Gloor, M., Mahlman, J., Pacala, S., Sarmiento, J., Takahashi, T., and Tans, P.: A large terrestrial carbon sink in North America implied by atmospheric and oceanic carbon dioxide data and models, Science, 282, 442-446, 1998.

Feely, R. A., Wanninkhof, R., Takahashi, T., and Tans, P.: Influence of El Nino on the equatorial Pacific contribution to atmospheric $\mathrm{CO}_{2}$ accumulation, Nature, 398, 597-601, 1999.

Feely, R. A., Boutin, J., Cosca, C. E., Dandonneau, Y., Etcheto, J., Inoue, H. Y., Ishii, M., Le Quere, C., Mackey, D. J., McPhaden, M., Metzl, N., Poisson, A., and Wanninkhof, R.: Seasonal and interannual variability of $\mathrm{CO}_{2}$ in the equatorial Pacific, DeepSea Res. Pt. II, 49, 2443-2469, 2002.

Gelb, A.: Applied Optimal Estimation, MIT Press, Cambridge, MA, 1974

Gurney, K., Baker, D., Rayner, P., and Denning, S.: Interannual variations in continental-scale net carbon exchange and sensitivity to observing networks estimated from atmospheric $\mathrm{CO}_{2}$ inversions for the period 1980 to 2005, Global Biogeochem. Cy., 22, GB3025, doi:10.1029/2007GB003082, 2008.

Gurney, K. R., Law, R., Rayner, P. J., and Denning, A. S. TransCom 3 Experimental Protocol, Tech. Rep. Paper No. 707, Department of Atmospheric Science, Colorado State University, USA, 2000.

Gurney, K. R., Law, R. M., Denning, A. S., Rayner, P. J., Baker D., Bousquet, P., Bruhwiler, L., Chen, Y. H., Ciais, P., Fan, S., Fung, I. Y., Gloor, M., Heimann, M., Higuchi, K., John, J., Maki, T., Maksyutov, S., Masarie, K., Peylin, P., Prather, M. Pak, B. C., Randerson, J., Sarmiento, J., Taguchi, S., Takahashi, T., and Yuen, C. W.: Towards robust regional estimates of $\mathrm{CO}_{2}$ sources and sinks using atmospheric transport models, Nature, 415, 626-630, 2002.

Gurney, K. R., Law, R. M., Denning, A. S., Rayner, P. J., Baker, D., Bousquet, P., Bruhwiler, L., Chen, Y. H., Ciais, P., Fan, S. M., Fung, I. Y., Gloor, M., Heimann, M., Higuchi, K., John, J., Kowalczyk, E., Maki, T., Maksyutov, S., Peylin, P., Prather, M., Pak, B. C., Sarmiento, J., Taguchi, S., Takahashi, T., and Yuen, C. W.: TransCom $3 \mathrm{CO}_{2}$ inversion intercomparison: 1 . Annual mean control results and sensitivity to transport and prior flux information, Tellus B, 55, 555-579, 2003.

Gurney, K. R., Law, R. M., Denning, A. S., Rayner, P. J., Pak, B. C., Baker, D., Bousquet, P., Bruhwiler, L., Chen, Y. H., Ciais, P., Fung, I., Heimann, M., John, J., Maki, T., Maksyutov, S., Peylin, P., Prather, M., and Taguchi, S.: Transcom 3 inversion intercomparison: model mean results for the estimation of seasonal 
carbon sources and sinks, Global Biogeochem. Cy., 18, GB1010, doi:10.1029/2003GB002111, 2004.

Heimann, M. and Koerner, S.: The global atmospheric tracer model TM3, model description and users manual, release 3.8a, Tech. Rep. Tech Rep. No. 5, Max Planck Institute for Biogeochemistry (MPIBGC), 2003.

Houghton, J. T., Ding, Y., Griggs, D., Noguer, M., van der Linden, P., Dai, X., Maskell, K., and Johnson, C. (Eds.): Climate change 2001: the scientific basis. Contribution of working group I to the third assessment report of the intergovernmental panel on climate change, Cambridge University Press, New York, 2001.

Jacobson, A. R., Mikaloff Fletcher, S. E., Gruber, N., Sarmiento, J. L., and Gloor, M.: A joint atmosphere-ocean inversion for surface fluxes of carbon dioxide: 2. Regional results, Global Biogeochem. Cy., 21, GB2025, doi:10.1029/2006GB002703, 2007.

Kalman, R.: A new approach to linear filtering and prediction problems, J. Basic Eng.-T. ASME, 82D, 35-45, 1960.

Kaminski, T., Heimann, M., and Giering, R.: A coarse grid threedimensional global inverse model of the atmospheric transport 2. Inversion of the transport of $\mathrm{CO}_{2}$ in the $1980 \mathrm{~s}, \mathrm{~J}$. Geophys. Res.-Atmos., 104, 18555-18581, 1999.

Kaminski, T., Rayner, P. J., Heimann, M., and Enting, I. G.: On aggregation errors in atmospheric transport inversions, J. Geophys. Res.-Atmos., 106, 4703-4715, 2001.

Keeling, C. D., Whorf, T. P., Wahlen, M., and Vanderplicht, J.: Interannual Extremes in the Rate of Rise of Atmospheric CarbonDioxide since 1980, Nature, 375, 666-670, 1995.

Keeling, R. F. and Shertz, S. R.: Seasonal and Interannual Variations in Atmospheric Oxygen and Implications for the Global Carbon-Cycle, Nature, 358, 723-727, 1992.

Krakauer, N., Schneider, T., Randerson, J., and Olsen, S. C.: Using generalized cross-validation to select parameters in inversions for regional carbon fluxes, Geophys. Res. Lett., 31, L19108, doi:10.1029/2004GL020323, 2004.

Louis, J. F.: A parametric model of vertical eddy fluxes in the atmosphere, Bound.-Lay. Meteorol., 17, 178-202, 1979.

Masarie, K. A. and Tans, P. P.: Extension and Integration of Atmospheric Carbon-Dioxide Data into a Globally Consistent Measurement Record, J. Geophys. Res.-Atmos., 100, 11593-11610, 1995.

Menke, W.: Geophysics Data Analysis: Discrete Inverse Theory, vol. 45, International Geophysics Series, Academic Press, San Diego, revised edition, 1989.

Michalak, A., Bruhwiler, L., and Tans, P.: A geostatistical approach to surface flux estimation of atmospheric trace gases, J. Geophys. Res.-Atmos., 109, D14109, doi:10.1029/2003JD004422, 2004.

Michalak, A. M., Hirsch, A., Bruhwiler, L., Gurney, K. R., Peters, W., and Tans, P.: Maximum likelihood estimation of covariance parameters for Bayesian atmospheric trace gas surface flux inversions, J. Geophys. Res.-Atmos., 110, D24107 doi:10.1029/2005JD005970, 2005.

Patra, P., Ishizawa, M., Maksyutov, S., Nakazawa, T., and Inoue, G.: Role of biomass burning and climate anomalies for land-atmosphere carbon fluxes based on inverse modeling of atmospheric $\mathrm{CO}_{2}$, Global Biogeochem. Cy., 19, GB3005, doi:10.1029/2004GB002258, 2005.

Patra, P., Gurney, K., Denning, A. S., Maksyutov, S., Nakazawa, T., Baker, D., Bousquet, P., Bruhwiler, L., Chen, Y.-H., Ciais, P., Fan, S., Fung, I., Gloor, M., Heimann, M., Higuchi, K., John, J.,
Law, R., Maki, T., Pak, B., Peylin, P., Prather, M., Rayner, P., Sarmiento, J., Taguchi, S., Takahashi, T., and Yuen, C.-W.: Sensitivity of inverse estimation of annual mean $\mathrm{CO}_{2}$ sources and sinks to ocean-only sites versus all-sites observational networks, Geophys. Res. Lett., 33, L05814, doi:10.1029/2005GL025403, 2006.

Peters, W., Miller, J., Whitaker, J., Denning, A., Hirsch, A., Krol, M., Zupanski, D., Bruhwiler, L., and Tans, P.: An ensemble data assimilation system to estimate $\mathrm{CO}_{2}$ surface fluxes from atmospheric trace gas observations, J. Geophys. Res., 110, D24304 doi:10.1029/2005JD006157, 2005.

Petron, G., Granier, C., Khattatov, B., Lamarque, J. F., Yudin, V., Muller, J. F., and Gille, J.: Inverse modeling of carbon monoxide surface emissions using Climate Monitoring and Diagnostics Laboratory network observations, J. Geophys. Res.-Atmos., 107, D244761, doi:10.1029/2001JD001305, 2002.

Peylin, P., Baker, D., Sarmiento, J., Ciais, P., and Bousquet, P.: Influence of transport uncertainty on annual mean and seasonal inversions of atmospheric $\mathrm{CO}_{2}$ data, J. Geophys. Res.-Atmos., 107(D19), 4385, doi:10.1029/2001JD000857, 2002.

Peylin, P., Bousquet, P., Le Quere, C., Sitch, S., Friedlingstein, P., McKinley, G., Gruber, N., Rayner, P. J., and Ciais, P.: Multiple constraints on regional co2 flux variations over land and oceans, Global Biogeochem. Cy., 19, GB1011, doi:10.1029/2003GB002214, 2005.

Randerson, J., Thompson, M., Conway, T., Fung, I., and Field, C.: The contribution of terrestrial sources and sinks to trends in the seasonal cycle of atmospheric carbon dioxide, Global Biogeochem. Cy., 11, 535-560, 1997.

Rayner, P., Enting, I., Francey, R., and Langenfelds, R.: Reconstructing the recent carbon cycle from atmospheric $\mathrm{CO}_{2}, \mathrm{~d}^{13} \mathrm{C}$ and $\mathrm{O}_{2} / \mathrm{N}_{2}$ observations, Tellus, 51B, 213-232, 1999.

Rayner, P., Scholze, M., Knorr, W., Kaminski, T., Giering, R., and Widmann, H.: Two decades of terrestrial carbon fluxes from a carbon cycle data assimilation system (CCDAS), Global Biogeochem. Cy., 19, GB2026, doi:10.1029/2004GB002254, 2005.

Rayner, P., Law, R., Allison, C., Francey, R., Trudinger, C., and Pickett-Heaps, C.: Interannual variability of the global carbon cycle (1992-2005) inferred by inversion of atmospheric $\mathrm{CO}_{2}$ and $\mathrm{d}^{13} \mathrm{C}$ measurements, Global Biogeochem. Cy., 22, GB3008, doi:10.1029/2007GB003068, 2008.

Rayner, P. J. and Law, R. M.: The interannual variability of the global carbon cycle, Tellus B, 51, 210-212, 1999.

Rödenbeck, C., Houweling, S., Gloor, M., and Heimann, M.: $\mathrm{CO}_{2}$ flux history 1982-2001 inferred from atmospheric data using a global inversion of atmospheric transport, Atmos. Chem. Phys., 3, 1919-1964, doi:10.5194/acp-3-1919-2003, 2003a.

Rödenbeck, C., Houweling, S., Gloor, M., and Heimann, M.: Timedependent atmospheric $\mathrm{CO}_{2}$ inversions based on interannually varying tracer transport, Tellus B, 55, 488-497, 2003b.

Rodgers, C. D.: Inverse methods for atmospheric sounding, vol. 2, Series on Atmospheric, Oceanic and Planetary Physics, World Scientific, London, 2000.

Russell, G. and Lerner, J.: A new finite-differencing scheme for the tracer transport equation, J. Appl. Meteorol., 20, 1483-1498, 1981.

Stephens, B. B., Gurney, K., Tans, P., Sweeney, C., Peters, W., Bruhwiler, L., Ciais, P., Ramonet, M., Bousquet, P., Nakazawa, T., Aoki, S., Machida, T., Inoue, G., Vinnichenko, N., Lloyd, 
J., Jordan, A., Heimann, M., Shibistova, O., Langenfelds, R. L., Steele, L. P., Francey, R. J., and Denning, A. S.: Weak Northern and Strong Tropical Land Carbon Uptake from Vertical Profiles of Atmospheric $\mathrm{CO}_{2}$, Science, 316, 1732-1735, 2007.

Takahashi, T., Wanninkhof, R., Feely, R. A., Weiss, R. F., Chipman, D., Bates, N., Olafsson, J., Sabine, C., and Sutherland, S. C.: Net sea-air $\mathrm{CO}_{2}$ flux over the global oceans: An improved estimate based on the sea-air $\mathrm{pCO}_{2}$ difference, in: 2 nd $\mathrm{CO}_{2}$ in Oceans Symposium, Natl. Inst. Environ. Stud., Tsukuba, Japan, 1999.

Takahashi, T., Sutherland, S. C., Sweeney, C., Poisson, A., Metzl, N., Tilbrook, B., Bates, N., Wanninkhof, R., Feely, R. A., Sabine, C., Olafsson, J., and Nojiri, Y.: Global sea-air $\mathrm{CO}_{2}$ flux based on climatological surface ocean $\mathrm{pCO}_{2}$, and seasonal biological and temperature effects, Deep-Sea Res. Pt. I, 49, 1601-1622, 2002.

Tans, P., Conway, T., and Nakazawa, T.: Latitudinal Distribution of the Sources and Sinks of Atmospheric Carbon Dioxide Derived from Surface Observations and an Atmopsheric Model, J. Geophys. Res.-Atmos., 94, 5151-5172, 1989.

Tans, P. P., Fung, I. Y., and Takahashi, T.: Observational Constraints on the Global Atmospheric $\mathrm{CO}_{2}$ Budget, Science, 247, 14311438, 1990.

Tarantola, A.: Inverse Problem Theory, Elsevier, New York, 1987.

Thoning, K. W., Tans, P. P., and Komhyr, W. D.: Atmospheric Carbon-Dioxide at Mauna Loa Observatory 2. Analysis of the NOAA GMCC Data, 1974-1985, J. Geophys. Res.-Atmos., 94, 8549-8565, 1989.
Tiedke, M.: A Comprehensive Mass Flux Scheme for Cumulus Parameterization in Large-Scale Models, Mon. Weather Rev., 117, 1779-1800, 1989.

van der Werf, G. R., Randerson, J. T., Collatz, G. J., Giglio, L., Kasibhatla, P. S., Arellano, A. F., Olsen, S. C., and Kasischke, E. S.: Continental-scale partitioning of fire emissions during the 1997 to $2001 \mathrm{El}$ Nino/La Nina Period, Science, 303, 73-76, 2004.

Wanninkhof, R.: Relationship between wind speed and gas exchange, J. Geophys. Res., 97, 7373-7382, 1992.

Wolter, K. and Timlin, M.: Monitoring ENSO in COADS with a seasonally adjusted principle component index, in: 17th Climate Diagnostics Workshop, University of Oklahoma, Norman, OK, 52-57, 1993.

Wolter, K. and Timlin, M.: Measuring the strength of ENSO -how does 1997/98 rank?, Weather, 53, 315-324, 1998.

Yuen, C. W., Higuchi, K., and Modellers, T.: Impact of Fraserdale $\mathrm{CO}_{2}$ Observations on annual flux inversion of the North American Boreal Region, Tellus, 57B, 203-209, 2005.

Zeng, X.: the relationship among precipitation, cloud-top temperature, and precipitable water over the tropics, J. Climate, 12, 2503-2514, 1999. 